ARTICLE

\title{
Palmitoyl acyltransferase DHHC21 mediates endothelial dysfunction in systemic inflammatory response syndrome
}

Richard S. Beard Jr. ${ }^{1, \star}$, Xiaoyuan Yang ${ }^{1, \star}$, Jamie E. Meegan ${ }^{1}$, Jonathan W. Overstreet ${ }^{1}$, Clement G.Y. Yang ${ }^{2}$, John A. Elliott ${ }^{1}$, Jason J. Reynolds ${ }^{1}$, Byeong J. Cha ${ }^{1}$, Christopher D. Pivetti ${ }^{3}$, David A. Mitchell ${ }^{4}$, Mack H. Wu ${ }^{2,5}$, Robert J. Deschenes ${ }^{4} \&$ Sarah Y. Yuan ${ }^{1,2}$

Endothelial dysfunction is a hallmark of systemic inflammatory response underlying multiple organ failure. Here we report a novel function of DHHC-containing palmitoyl acyltransferases (PATs) in mediating endothelial inflammation. Pharmacological inhibition of PATs attenuates barrier leakage and leucocyte adhesion induced by endothelial junction hyperpermeability and ICAM-1 expression during inflammation. Among $11 \mathrm{DHHCs}$ detected in vascular endothelium, DHHC21 is required for barrier response. Mice with DHHC21 function deficiency (Zdhhc21 $1^{\text {dep} / d e p)}$ exhibit marked resistance to injury, characterized by reduced plasma leakage, decreased leucocyte adhesion and ameliorated lung pathology, culminating in improved survival. Endothelial cells from Zdhhc2 $1^{\text {dep/dep }}$ display blunted barrier dysfunction and leucocyte adhesion, whereas leucocytes from these mice did not show altered adhesiveness. Furthermore, inflammation enhances PLC $\beta 1$ palmitoylation and signalling activity, effects significantly reduced in Zdhhc21dep/dep and rescued by DHHC21 overexpression. Likewise, overexpression of wild-type, not mutant, PLC $\beta 1$ augments barrier dysfunction. Altogether, these data suggest the involvement of DHHC21-mediated PLC $\beta 1$ palmitoylation in endothelial inflammation.

\footnotetext{
${ }^{1}$ Department of Molecular Pharmacology and Physiology, Morsani College of Medicine, University of South Florida, Tampa, Florida 33612, USA. ${ }^{2}$ Department of Surgery, Morsani College of Medicine, University of South Florida, Tampa, Florida 33612, USA. ${ }^{3}$ Department of Surgery, School of Medicine, University of California at Davis, Sacramento, California 95817, USA. ${ }^{4}$ Department of Molecular Medicine, Morsani College of Medicine, University of South Florida, Tampa, Florida 33612, USA. ${ }^{5}$ James A. Haley Veterans' Hospital, Tampa, Florida 33612, USA. * These authors contributed equally to this work. Correspondence and requests for materials should be addressed to S.Y. (email: syuan@health.usf.edu).
} 
M any critically ill patients present with systemic inflammatory response syndrome (SIRS), one of the most challenging conditions resulting from infection (sepsis) or non-infectious injury (trauma, pancreatitis, haemorrhage $)^{1-3}$. Despite improved patient care, their mortality and morbidity remain high owing to the development of multiple organ failure. Following injury, SIRS is triggered by an array of danger-associated molecular patterns and mediators released into the circulation, including histamine, thrombin and cytokines, most of which target vascular endothelium causing microvascular leakage, coagulopathy and leucocyte diapedesis ${ }^{4}$. Multiple etiologies and complex receptor-signalling pathways are attributed to this disease state; however, therapies directed at targeting the upstream of inflammatory cascades (cytokine inhibitors, histamine antagonists, so on) show limited efficacy ${ }^{1,3,5}$. Likewise, blockades of innate immunity (TLR4 antagonist) or coagulation (anti-thrombin) fail to demonstrate improved survival ${ }^{6,7}$. Recently, recognizing the central role of endothelial dysfunction in inflammation, the FDA approved recombinant human activated protein $\mathrm{C}$ for treating sepsis. Unfortunately, it was quickly withdrawn due to minimal mortality benefit and increased bleeding risk ${ }^{8}$. Currently, several new therapies, including anti-HMGB1 and sphingosine-1phosphate analogous are being investigated ${ }^{1,3,9,10}$; many of them are not designed to specifically treat endothelial dysfunction. The underdevelopment of endothelial-targeting interventions highlights the need for further studies.

A hallmark of endothelial dysfunction during SIRS is opening of cell-cell junctions promoting plasma and leucocyte extravasation. Because barrier breakdown or loosening often occurs rapidly (within minutes) after stimulation, it is plausible that dynamic modifications of the endothelial barrier serve as the major mechanism for vascular hyperpermeability ${ }^{11-13}$. Many studies have focused on phosphorylation of molecules involved in the initial establishment of barrier structure or upstream signalling such as kinase receptors ${ }^{14-16}$. However, it is becoming increasingly apparent that phosphorylation alone may not account for all signalling or structural changes in the barrier under infectious or injurious conditions $s^{17-19}$. The purpose of this study is to evaluate our hypothesis that another dynamic regulatory mechanism, namely protein palmitoylation, plays a critical role in altering endothelial function during inflammation.

Palmitoyl acyltransferases (PATs) are a family of enzymes that catalyse protein S-palmitoylation, a thioester linkage of palmitic acid to cysteine residues. All PATs share a signature catalytic domain containing a zinc finger aspartate-histidine-histidinecysteine (DHHC) motif ${ }^{20}$. Since the initial discovery of a DHHC-PAT in yeast by Roth $^{21}$ and Deschenes ${ }^{22}$, the DHHC family has grown to 23 members in human and 24 in mouse genomes. Functionally, PAT-catalysed palmitoylation is shown to rapidly change protein locations, activity and ability to interact with other proteins ${ }^{23}$. Recent studies of palmitoylation kinetics have underscored the potential of PATs as a 'kinase-like' factor in signal transduction ${ }^{24-27}$. So far, the biologic effects of PATs have been primarily investigated in the fields of cell growth, lipid metabolism and neuroscience. Studies have also reported their involvement in Wnt-driven carcinogenesis ${ }^{28}$, insulin-promoted angiogenesi ${ }^{29}$, neurologic diseases ${ }^{30}$ and metabolic disorders ${ }^{31,32}$. Most recently, an in vivo study demonstrated a role for DHHC21-PAT in mediating vasoconstriction by palmitoylating $\alpha$-adrenergic receptor ${ }^{33}$, suggesting the possibility that PATs serve as an important dynamic regulator of circulatory functions.

Since there is currently no direct evidence for PATs regulating endothelial function during inflammation, we sought to determine if and how PATs affect vascular barrier properties and leucocyte-endothelium interactions under SIRS relevant conditions, using animal models of systemic inflammation caused by traumatic injury (burns) and septic insult (LPS injection), as well as microvessels and endothelial monolayers stimulated by typical inflammatory mediators (histamine, thrombin or IL-1 $\beta$ ). Four sets of experiments were designed to study the DHHC21-PLC $\beta 1$ pathway in endothelial inflammation. In the first set of experiments, we evaluated the effects of general pharmacologic inhibition of PATs in vivo during trauma or endotoxemia and in vitro during inflammatory stimulation. We also verified the underlying cellular responses focusing on endothelial cell-cell junction permeability and ICAM-1 expression. In the second set of experiments, after confirming the expression of individual PATs in vascular endothelium, we conducted a functional screening in endothelial monolayers subjected to individual gene knockdown to determine that the presence of specific PATs, namely DHHC21, is required for barrier responses. In the third set of experiments, we used a genetically modified mouse model of DHHC21 function deficiency ( $Z$ dhhc21 $1^{\text {dep/dep }}$ ) to evaluate the contribution of this PAT to SIRS-induced organ injury and mortality. The relative importance of endothelial-specific DHHC21 was also evaluated. In the fourth set of experiments, we identified PLC $\beta 1$ as a target of DHHC21. Further mechanistic studies were directed at measuring PLC $\beta 1$ palmitoylation, subcellular distribution and signalling activity in Zdhhc2 dep/dep cells. Moreover, comparisons were made in endothelial cells subjected to PLC $\beta 1$ knockdown, PLC $\beta 1$ wild-type overexpression and PLC $\beta 1$ C17 mutant overexpression to determine the mechanistic contribution of PLC $\beta 1$ to endothelial dysfunction. The results from these experiments show that protein palmitoylation plays a critical role in mediating aberrant activation of vascular endothelium during inflammation. We suggest targeting DHHC21 as potential therapy of inflammatory diseases.

\section{Results}

PAT inhibition prevents vascular barrier breakdown. Two-bromopalmitate (2-BP) is a general inhibitor of PAT activity that acts by suppressing the formation of acyl-intermediates ${ }^{34}$. To determine the pathophysiological involvement of PATs in inflammation, we tested the effects of 2-BP to reduce microvascular leakage. In healthy rats, intravenous administration of 2-BP did not cause mortality or obvious abnormalities in cardiorespiratory function or mesenteric circulation for the duration of our experiments. However, animals receiving 2-BP prior to SIRS induction displayed drastically reduced plasma extravasation through mesenteric vessels indicated by transvascular flux of FITC-albumin (Fig. 1a,b). Moreover, 2-BP ameliorated vascular barrier injury in the lungs, measured by tissue uptake of Evans Blue, a marker of albumin leakage (Fig. 1c,d), and by interstitial deposition of sulfo-NHS-biotin, a marker of small molecule efflux (Fig. 1e).

We then examined the effects of PAT inhibition on endothelial cell-cell adhesive barrier morphology and function in human umbilical vein endothelial cells (HUVEC) during inflammatory stimulation. Consistent with our in vivo findings, 2-BP inhibited barrier dysfunction, indicated by reduced transendothelial electrical resistance (indicator of cell-cell adhesive barrier property) in response to thrombin in a time-dependent and dose-related manner (Fig. 2a). Given that the barrier integrity of microvascular endothelium is largely determined by adherens junctions $(\mathrm{AJs})^{35}$, we focused on the changes in VE-cadherin, the primary AJ molecule. As shown in Fig. 2b, VE-cadherin staining under unstimulated conditions was characterized by continuous distribution at endothelial cell-cell contacts. Upon inflammatory stimulation by thrombin (Fig. 2b), it became discontinuous, 
a

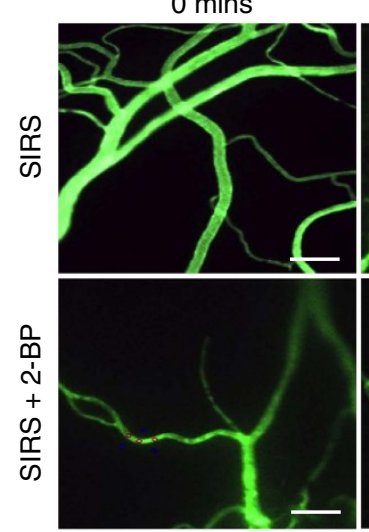

30 mins

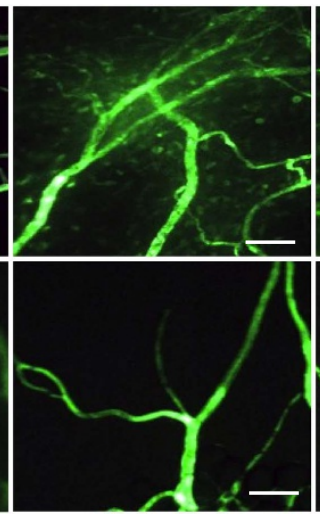

60 mins

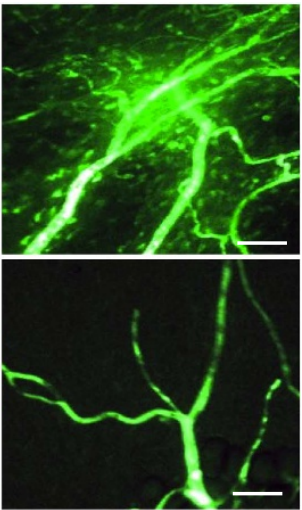

b $\quad$ SIRS + Vehicle $n=6$

$\widehat{\bar{D}} \Delta .5 \mathrm{SIRS}+2-\mathrm{BP} \mathrm{n}=6$

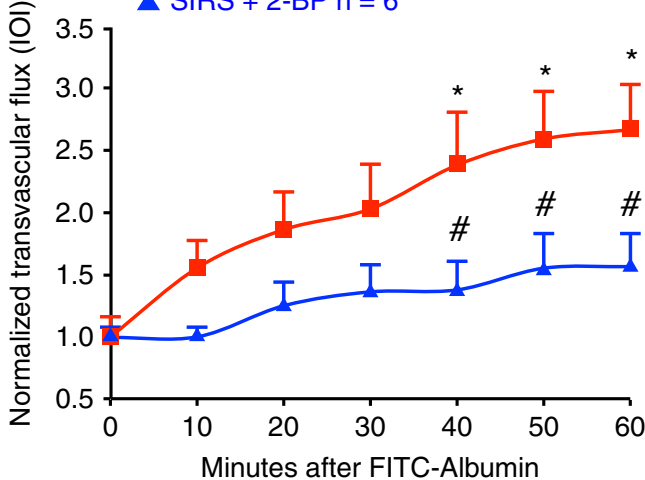

d

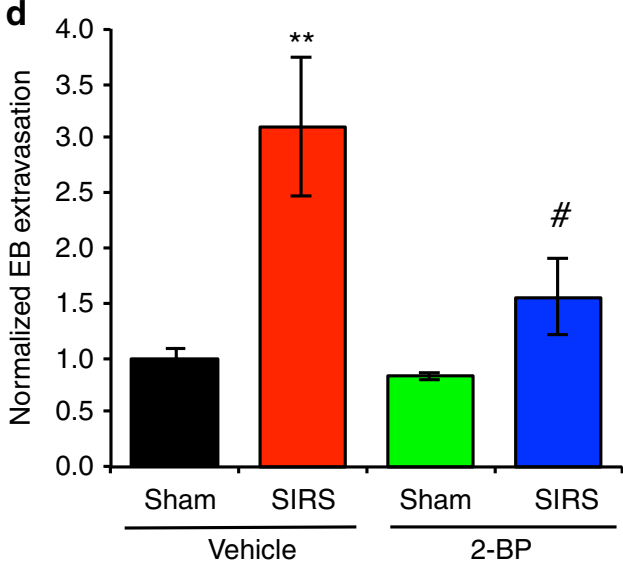

2-BP SIRS + 2-BP

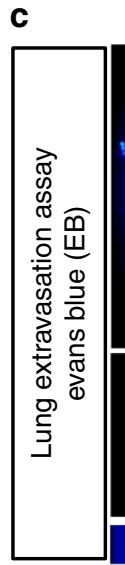

Sham

SIRS

2-BP

$\mathrm{SIRS}+2-\mathrm{BP}$

Whole left lung lobes

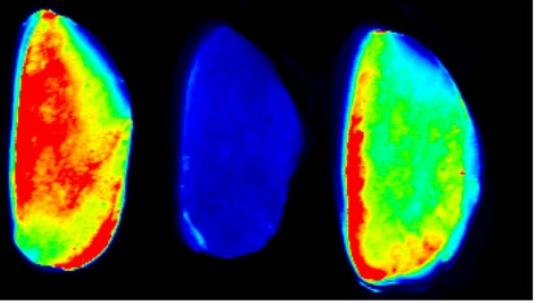

Transverse Sections ( $1 \mathrm{~mm})$

Signal intensity @ 700 nm

$\longrightarrow$

No tracer Sham SIRS

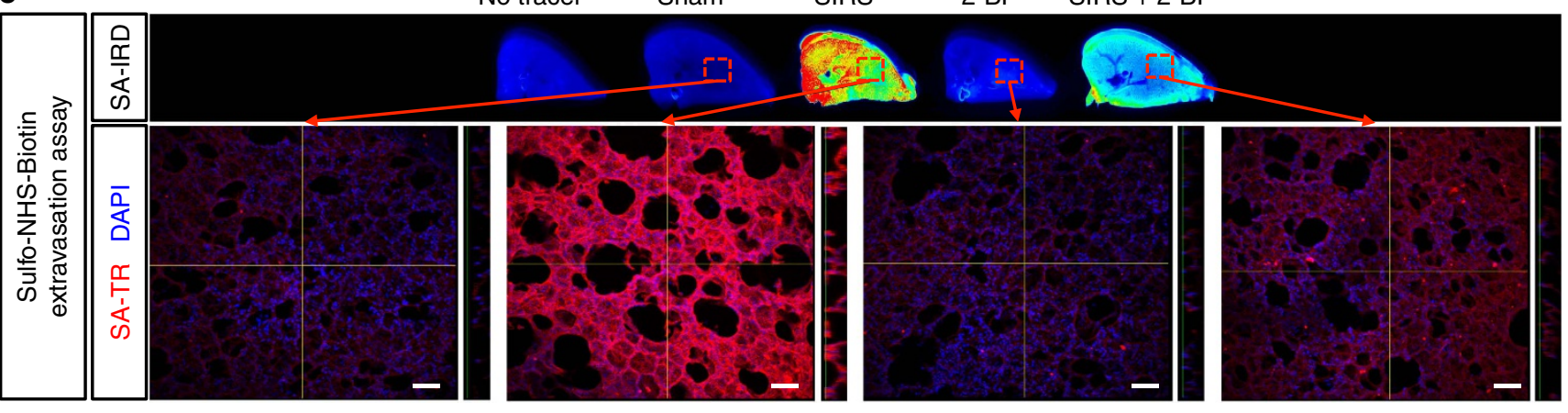

Figure 1 | Inhibition of PATs attenuates microvascular leakage during systemic inflammatory response to burn injury. The palmitoyl acyltransferase inhibitor 2-bromopalmitate (2-BP, $2 \mathrm{mg} \mathrm{kg}^{-1}$ ) was intravenously administrated 20 min prior to SIRS induction. (a,b) Transvascular flux of FITC-albumin from mesenteric microvessels observed via intravital microscopy $3 \mathrm{~h}$ postburn. (a) Representative images (Scale bars, $100 \mu \mathrm{m}$ ). (b) Quantification of transvascular flux ( $n=$ number of animals). For each group, values were normalized to its own $t=0$ min and presented as mean \pm s.e.m. ${ }^{\star} P<0.05$ versus sham + vehicle, ${ }^{\#} P<0.05$ versus SIRS + vehicle. (c,d) Plasma protein leakage in the lungs measured as tracer Evans Blue extravasation. (c) Representative images showing tracer leakage captured at $700 \mathrm{~nm}$ with infrared imaging scanner and pseudo-colored with a heat-map colour scheme. (d) Quantitative extravasation assay $(n=6)$. Values were normalized to vehicle-treated group subjected to sham operation and presented as mean \pm s.e.m. ${ }^{\star \star} P<0.01$ versus sham + vehicle, ${ }^{\#} P<0.05$ versus SIRS + vehicle. (e) Microvascular leakage in the lungs measured as interstitial deposition of small molecule tracer sulfo-NHS-biotin. Upper panels: representative transverse lung slices $(500 \mu \mathrm{m})$ probed for extravasated sulfo-NHS-biotin with IRDye 800 -conjugated streptavidin (SA-IRD) and scanned with infrared imaging system $(800 \mathrm{~nm})$. Images were pseudo-colored with heat-map colour scheme $($ blue $=$ low intensity, red = high intensity). Lower panels: representative confocal micrographs of lung sections probed for sulfo-NHS-biotin with Texas Red-streptavidin (SA-TR). Nuclei were stained with DAPI. Scale bars, $100 \mu \mathrm{m}$.

diffuse or thinner. Intercellular gaps were formed (arrows). Quantitative results showed that 2-BP significantly reduced thrombin-induced junction discontinuity (Fig. 2c). Similar inhibitory effects of 2-BP on histamine-induced microvascular hyperpermeability (Fig. 2d) and junction dissociation were observed (Fig. 2e,f). Further, we confirmed the direct effects of
2-BP on intact postcapillary venules, which are known to serve as the major vascular bed for plasma leakage and leucocyte diapedesis during inflammation. Using a modified Landis micro-occlusion technique, we measured hydraulic conductivity $\left(L_{\mathrm{p}}\right.$; indicator of permeability to water filtration along pressure gradient) in single perfused venules. Perfusion of 2-BP 
a

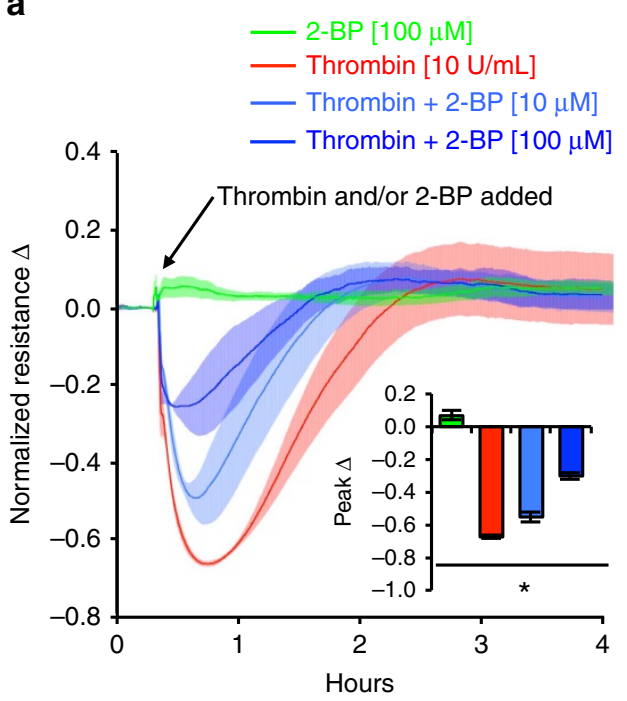

d

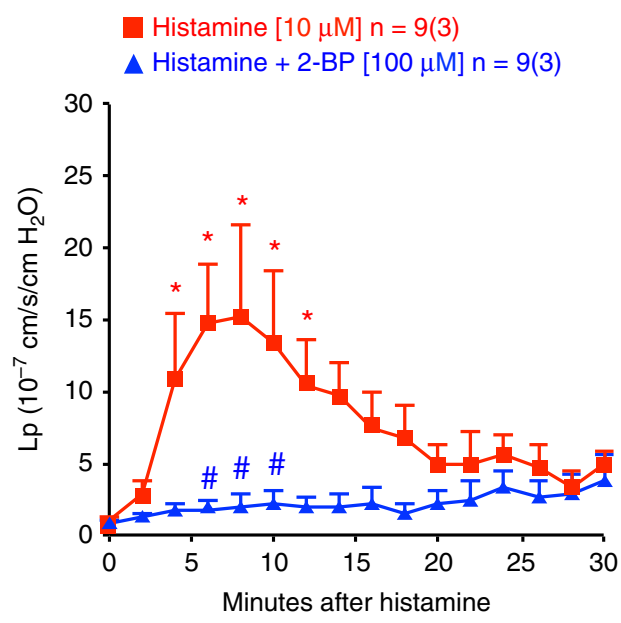

b

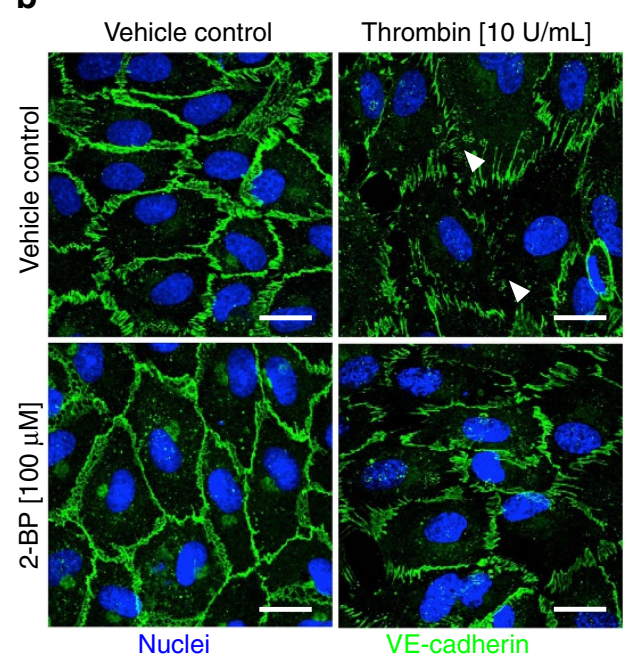

e

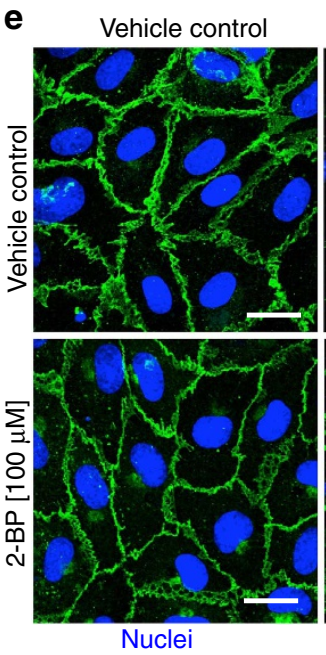

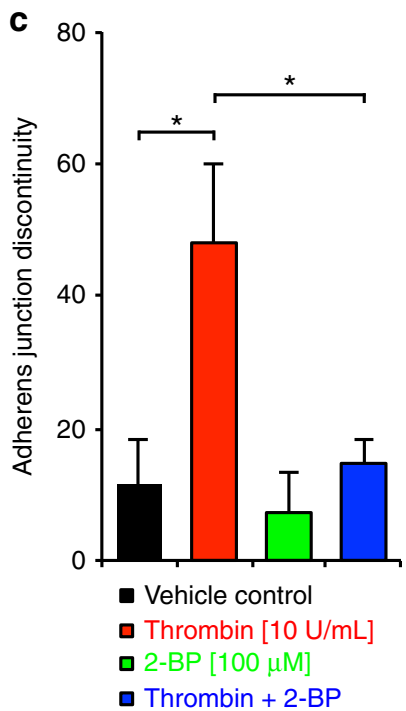

f

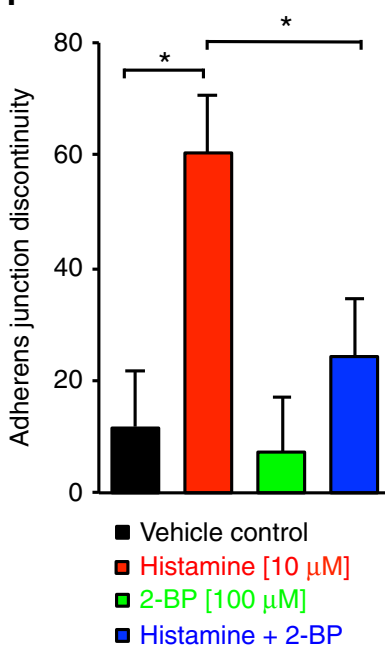

Figure 2 | Inhibition of PATs reduces inflammatory mediator-induced endothelial cell-cell junction hyperpermeability. (a) Time- and dose-dependent effects of 2-BP on thrombin $\left(10 \mathrm{U} \mathrm{ml}^{-1}\right)$-induced reduction in transendothelial electric resistance (TER), an indicator of cell-cell adhesive barrier function. Values at each time point were normalized to their baseline at $t=0$. Solid line tracing represents the mean resistance, and shadow represents standard error. Embedded graph indicates peak TER values and presented as mean \pm s.e.m. ( $n=3$ independent experiments). ${ }^{\star} P<0.05$. (b) Representative confocal images of the adherens junction molecule VE-cadherin (green) and nuclei (blue) 30 min after thrombin with or without pretreatment of 2-BP. Arrows point to discontinued VE-cadherin strands or intercellular gaps. Scale bars, $10 \mu \mathrm{m}$. (c) Quantification analysis of VE-cadherin junction discontinuity from three independent experiments, presented as mean \pm s.e.m. ${ }^{\star} P<0.05$. (d) Histamine-induced changes in hydraulic conductivity $\left(L_{p}\right)$ in intact perfused venules without or with 2-BP (given 30 min prior to histamine and continuously perfused until the end of the observation). $L_{p}$ indicates venular permeability to water which transports mainly via paracellular pathway. $n=$ number of segment measurements; values in parentheses indicate number of independent experiments. ${ }^{\star} P<0.05$ versus baseline, ${ }^{\#} P<0.05$ versus histamine + vehicle. (e) Representative confocal images of VE-cadherin (green) and nuclei (blue) 10 min after histamine in endothelial cells pre-treated with 2-BP. Arrows point to discontinued VE-cadherin strands or intercellular gaps. Scale bars $=10 \mu \mathrm{m}$. (f) Quantification analysis of VE-cadherin junction discontinuity from three independent experiments. Data are presented as mean \pm s.e.m. ${ }^{\star} P<0.05$.

significantly reduced the increase in $L_{\mathrm{p}}$ caused by histamine (Fig. 2d), consistent with 2-BP attenuation of histamine-induced AJ disruption in vitro (Fig. 2e,f).

PAT inhibition reduces leucocyte adhesion/ICAM-1 expression. Leucocyte-endothelial interactions were observed in rat mesenteric microvessels via intravital microscopy (Fig. 3a). During inflammation slow-rolling leucocytes are more likely to be arrested by endothelial cells leading to firm adhesion. We thus evaluated the effects of PAT inhibition on leucocyte adhesion along with their slow-rolling flux, slow-rolling fraction and rolling velocity. As shown in Fig. 3b, SIRS significantly increased leucocyte adhesion and slow rolling. Compared with vehicletreated animals, 2-BP-pretreated animals demonstrated an attenuated response in leucocyte adhesion. Additionally, adhesion of human leucocytes to HUVEC monolayers after stimulation by interleukin-1 $\beta$ (IL-1 $\beta$ ) was measured. In basal conditions or cells treated with 2-BP alone, minimal adhesion was observed. However, after IL-1 $\beta$ stimulation, there was a significant increase in the number of adherent leucocytes; the response was attenuated by 2-BP treatment (Fig. 3c,d). Because ICAM-1 expression on the surface of endothelium is required for leucocyte adhesion, we also tested the efficacy of 2-BP to reduce ICAM-1 surface expression under these conditions. Indeed, there was a significant increase in endothelial cell surface expression of 
a
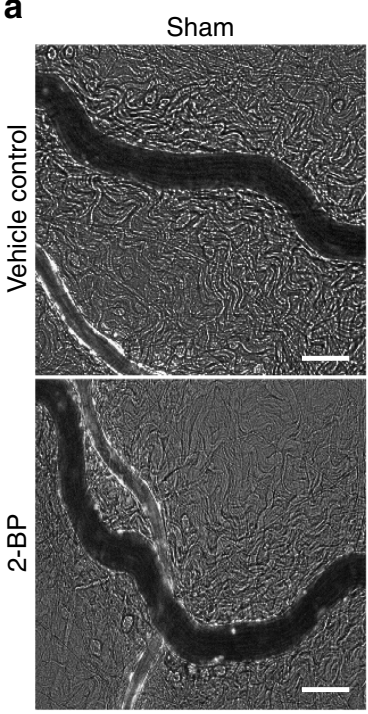

C

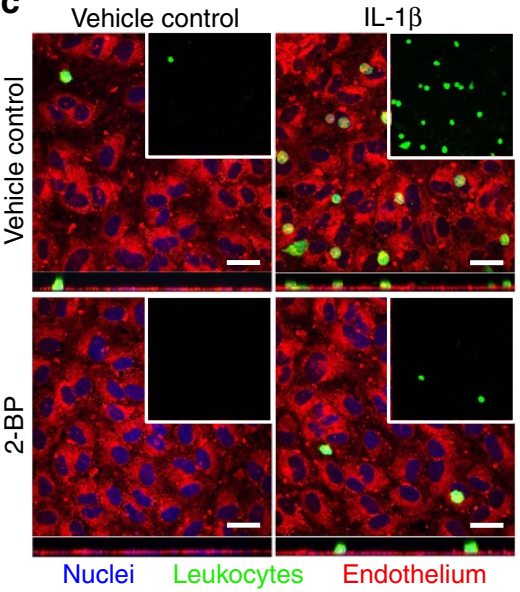

LPS-SIRS

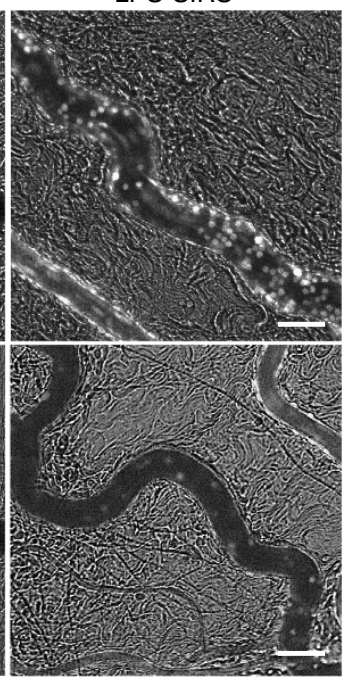

d

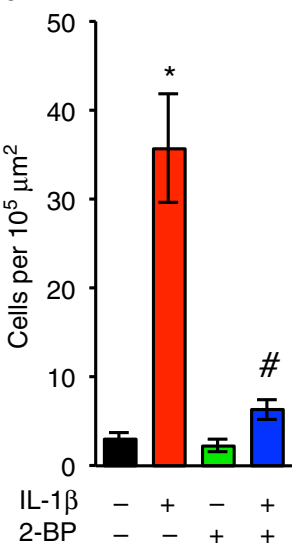

b
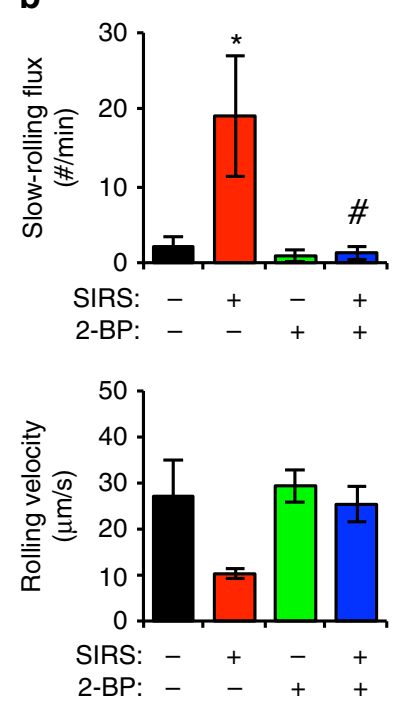

e

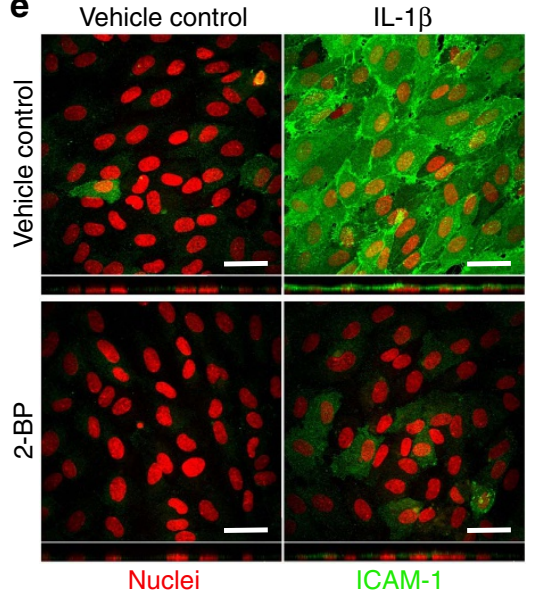

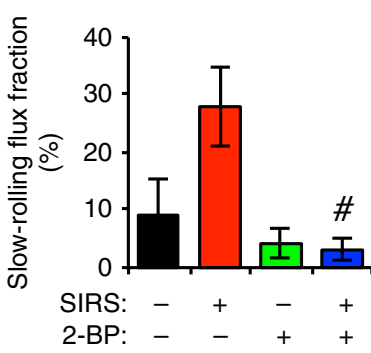

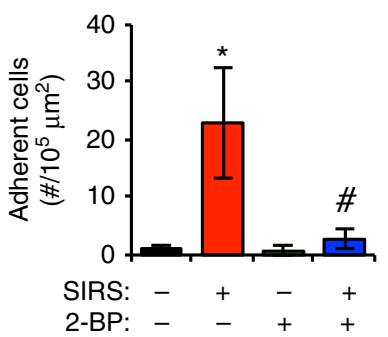

Figure 3 | PAT inhibition suppresses leucocyte adhesion and ICAM-1 expression on endothelial surface during inflammatory stimulation.

$(\mathbf{a}, \mathbf{b})$ Leucocyte-endothelium interactions were assessed via intravital microscopic analysis of mesenteric microcirculation in rats subjected to SIRS elicited by bacterial lipopolysaccharide (LPS, $10 \mathrm{mg} \mathrm{kg}^{-1}, \mathrm{IP}, 4 \mathrm{~h}$ ). A group of animals received intravenous 2-BP (2 mg kg ${ }^{-1}$ ) immediately after LPS injection. Leucocytes were labelled with acridine orange. (a) Representative images of leucocyte adhesion in postcapillary venules. Scale bars, $30 \mu \mathrm{m}$.

(b) Quantification of leucocyte slow-rolling flux (number of cells per min), slow-rolling fraction (\% of slow rolling cells to total rolling cells), rolling velocity and adhesion. Increased slow-rolling flux or decreased rolling velocity indicates the likelihood of firm adhesion. Data are presented as mean \pm s.e.m. from 4 rats with $\geq 10$ venules per group. ${ }^{\star} P<0.05$ versus sham + vehicle, ${ }^{\#} P<0.05$ versus SIRS + vehicle. (c,d) The effects of 2 -BP on human leucocyte adhesion to human umbilical vein endothelial cells with or without stimulation by IL-1 $\beta$ (100 $\left.\mathrm{ng} \mathrm{ml}^{-1}, 4 \mathrm{~h}\right)$. 2 -BP $(10 \mu \mathrm{M})$ or vehicle was given simultaneously with IL-1 3 . (c) Representative images of adherent leucocytes (green) on endothelial cells (red) with nuclei stained with DAPI. Embedded images show green channel (leucocytes) alone. Scale bars, $25 \mu \mathrm{m}$. (d) Quantification of adherent leucocytes to IL-1 $\beta$-stimulated ECs. Bar graph represents mean \pm s.e.m. from three independent experiments. ${ }^{\star} P<0.05$ versus unstimulated + vehicle, ${ }^{\#} P<0.05$ versus IL-1 $\beta+$ vehicle. (e,f) The effects of 2 -BP on IL-1 $\beta$-induced ICAM-1 expression on endothelial surface. Endothelial cells were treated with $100 \mathrm{ng} \mathrm{ml}-1 \mathrm{IL}-1 \beta$ for $4 \mathrm{~h}$ with or without $10 \mu \mathrm{M} 2-\mathrm{BP}$ (given simultaneously with IL-1 $\beta$ ). (e) Representative confocal images. Scale bars, $50 \mu$ m. (f) Quantification of ICAM-1 surface expression. Results represent mean \pm s.e.m. from three independent experiments. ${ }^{\star} P<0.05$ versus unstimulated + vehicle, ${ }^{\#} P<0.05$ versus IL-1 $\beta+$ vehicle.

ICAM-1 in response to IL-1 $\beta$, a response prevented by 2 -BP (Fig. 3e,f). Altogether, these findings indicate the involvement of DHHC-PATs in vascular inflammation.

Inflammation increases PLC $\beta 1$ palmitoylation and signalling. In an effort to quantify protein palmitoylation in endothelial cells, we employed Click chemistry to measure the level of total palmitoylated proteins in HUVECs under basal conditions and during stimulation by SIRS plasma or inflammatory agents (thrombin, histamine). Palmitoylated proteins were metabolically labelled with a palmitic acid analogue, $\omega$-alkynyl palmitic acid (Alk-C16), and further probed with fluorescent Oregon Green
488 azide by copper-catalysed click reaction for observation under confocal microscopy. The data showed that following inflammatory stimulation by histamine, thrombin or SIRS plasma, there was a significant increase in total palmitoylated proteins. Treatment with 2-BP prevented this response (Fig. 4a).

We then tried to identify specific proteins that undergo palmitoylation in inflammation. In initial screening, we conducted a proteomic analysis combining acyl-biotin exchange (ABE) with LC-MS/MS. ABE is a series of biochemical reactions involving the exchange of protein palmitoylation moieties with biotin, which can be detected via pull-down with streptavidin beads. We identified a protein that undergoes increased 
palmitoylation in endothelial cells upon SIRS stimulation, phospholipase C $\beta 1$ (PLC $\beta 1$ ), an important signalling molecule downstream of the G-protein coupled receptors (GPCR) known to mediate the effects of inflammatory mediators such as thrombin and histamine. Thus, we sought to focus on PLC $\beta 1$ in the following experiments. Our data demonstrated that thrombin induced a significant increase in PLC $\beta 1$ palmitoylation, which was inhibited by 2-BP treatment (Fig. 4b) (see full-scanned western blots and gels in Supplementary Figs 1-5). Consistently, a pull-down assay with azide agarose resin based on metabolic labelling and Click chemistry showed that histamine stimulation was able to increase the level of PLC $\beta 1$ palmitoylation (Fig. 4c). Since it is well established that PLC $\beta 1$ activation leads to IP3 production, we next examined the concomitant changes in IP3
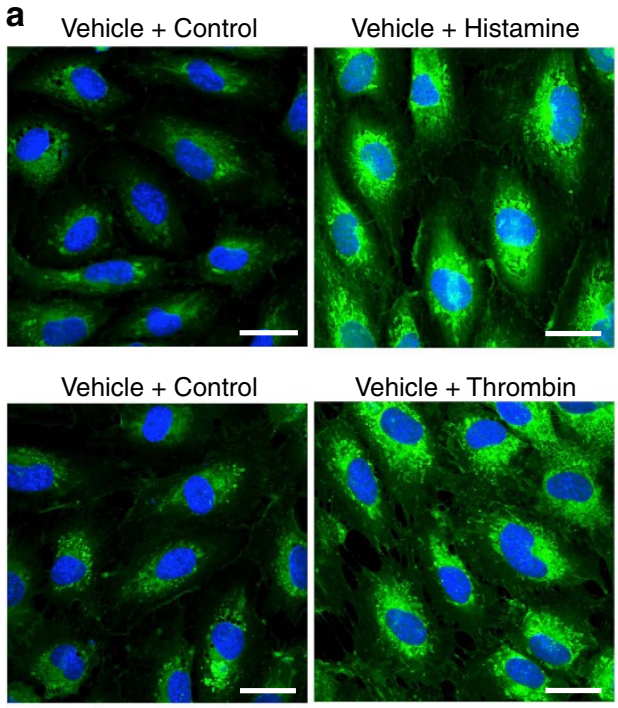

Vehicle + Thrombin

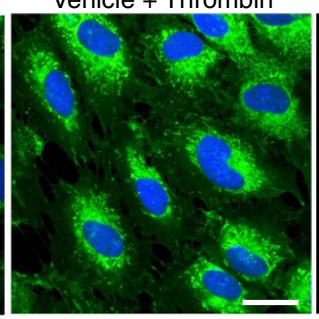

Vehicle + Sham plasma
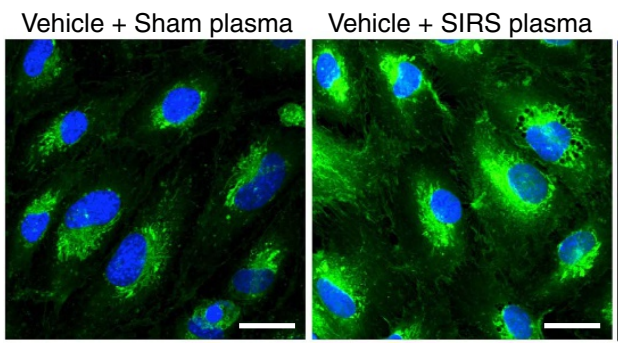

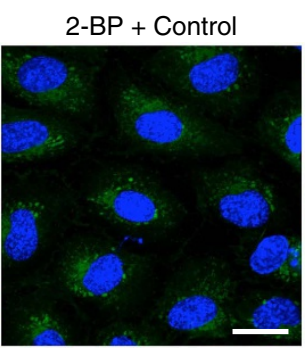

$2-\mathrm{BP}+$ Control
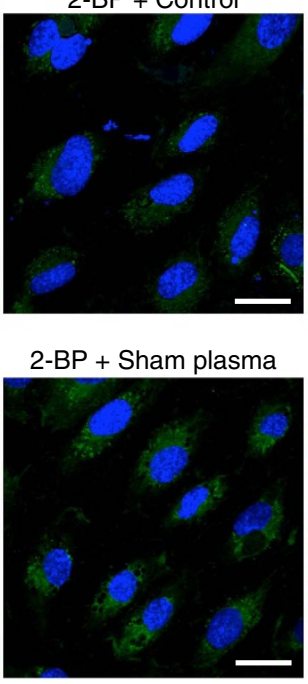

2-BP + Histamine

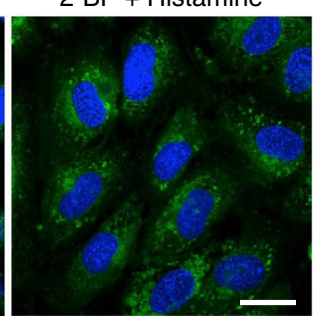

2-BP + Thrombin

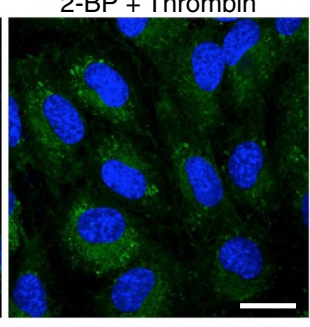

$2-B P+$ SIRS plasma

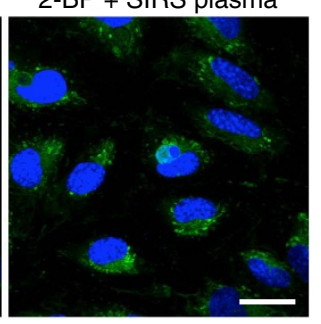

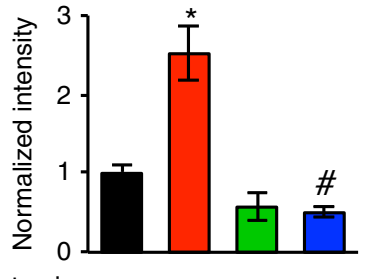

$\begin{array}{rrrrr}\text { Histamine } & - & + & - & + \\ 2-B P & - & - & + & +\end{array}$
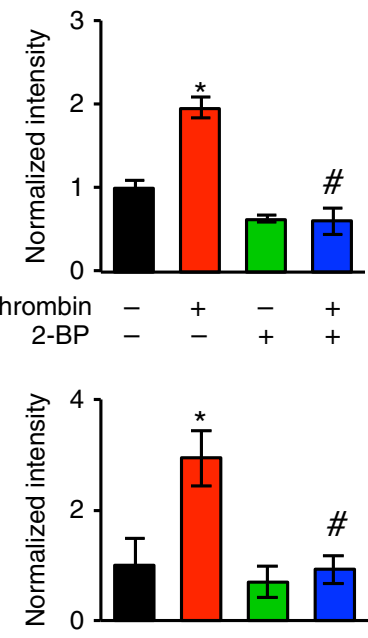

SIRS

Plasma

2-BP b

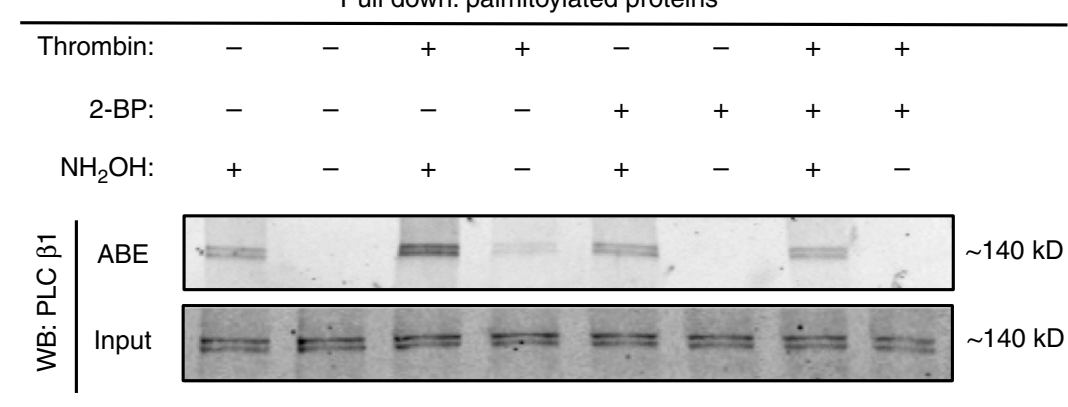

C

Pull down: palmitoylated proteins

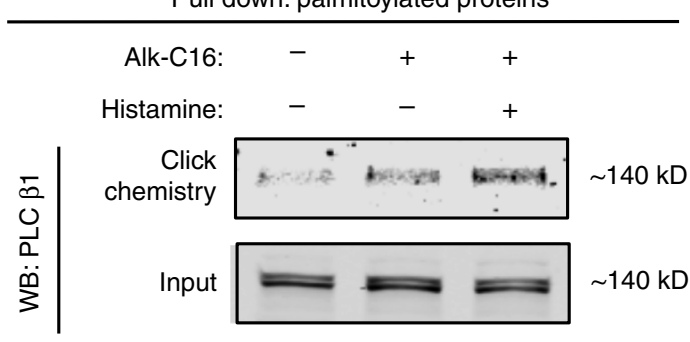

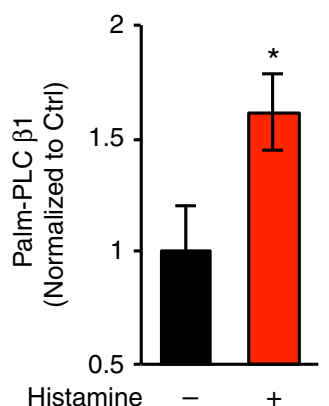

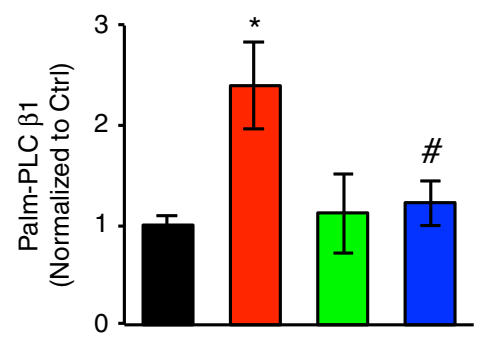

Thrombin - $\quad+\quad-\quad+$

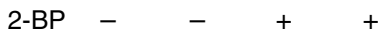

d

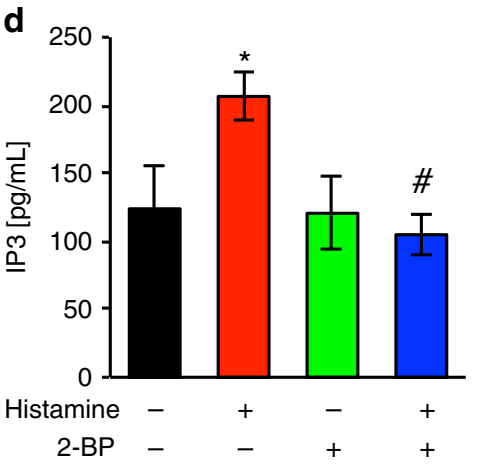


levels as an indicator of PLC $\beta 1$ signalling activity. The results showed that histamine increased IP3 production and this effect was not observed in cells treated with 2-BP (Fig. 4d), suggesting the potential involvement of palmitoylation-coupled PLC $\beta 1$ signalling activity in inflammation.

DHHC5/21 are critical in endothelial barrier response. More than 20 DHHC-PATs have been identified (Supplementary Table 1) and are known to have heterogeneous tissue distribution $^{36}$; however, their expression profile in the vascular endothelium has not been fully reported. In this study, we evaluated DHHC-PAT expression and function in murine lung microvascular endothelial cells (MLMVECs). Quantitative PCR was performed to characterize endothelial-specific $Z d h h c$ gene expression (Fig. 5a). Among the 24 known Zdhhcs, only Zdhhcs 2, $4,5,8,9,12,13,16,17,20$ and 21 were detected. To investigate which of these may regulate endothelial injury, we silenced their expression individually with siRNA and assessed the functional impact on thrombin-mediated endothelial barrier dysfunction and IL-1 $\beta$ upregulation of ICAM- 1 expression. The efficiency of the siRNA knockdown was confirmed by RT-PCR (Fig. 5b). Out of the 11 endothelial-expressing $Z d h h c s$, only knockdown of $Z d h h c 5$ or Zdhhc21 significantly ameliorated barrier dysfunction (Fig. 5c,d) and ICAM-1 expression (Fig. 5e,f). These data demonstrate an important role for DHHC5- and DHHC21PATs in endothelial response to inflammatory stimulation.

\section{$Z d h h c 21^{d e p / d e p}$ mice are resistant to organ injury in SIRS. After determining the importance of DHHC21 in inflammation- mediated endothelial injury, we focused on in vivo studies utilizing a DHHC21 deficient mouse model, $Z d h h c 21^{\text {dep/dep. Its }}$ genetic background involves a spontaneous $3 \mathrm{bp}$ deletion in the coding region of the $Z d h h c 21$ gene rendering DHHC21 function deficiency ${ }^{37}$. The effect of DHHC21 deficiency on overall SIRS outcomes was determined. Specifically, lung injury $24 \mathrm{~h}$ after SIRS-induction was evaluated by histological H\&E staining in both wild-type controls $\left(Z d h h c 21^{+/+}\right)$and $Z d h h c 21^{\text {dep/dep }}$ mice. In $Z d h h c 21^{+1+}$ mice, thickening of alveoli-capillary membrane and leucocyte infiltration were observed; these pathologies were significantly ameliorated in Zdhhc21 dep/dep mice (Fig. 6a-c,e). Furthermore, as shown in Fig. 6d, thermal injury-induced SIRS caused $\sim 30 \%$ mortality in Zdhhc $21^{+/+}$mice by $48 \mathrm{~h}$, whereas no deaths were observed in $Z d h h c 21^{\text {dep/dep }}$ mice during the same time course. Similarly, as shown in Fig. 6f, LPS-induced SIRS caused $100 \%$ mortality of $Z d h h c 21^{+/+}$mice within $60 \mathrm{~h}$, whereas there was still a $60 \%$ survival rate in $Z d h h c 21^{\text {dep/dep }}$ mice at $72 \mathrm{~h}$.}

Endothelial DHHC21 is important for leucocyte adhesion. To evaluate the effects of DHHC21 deficiency in leucocyteendothelial interactions, we measured leucocyte rolling and adhesion in postcapillary venules of $Z d h h c 21^{+/+}$and $Z d h h c 21^{\text {dep/dep }}$ mouse ears. Zdhhc21 dep/dep mice displayed basal circulatory characteristics comparable to wild-type controls, but with a blunted vascular injurious response to SIRS. In Zdhhc $21^{+/+}$mice subjected to burn- or LPS-induced SIRS, the number of slow-rolling leucocytes, the fraction of slow-rolling leucocytes and leucocyte adhesion to the microvessel wall were significantly increased, and the average leucocyte rolling velocity was greatly reduced; however, $Z d h h c 21^{\text {dep/dep }}$ mice were resistant to these responses (Fig. 7a,b).

Furthermore, primary MLMVECs and leucocytes were isolated from $Z d h h c 21^{+1+}$ and $Z d h h c 21^{\text {dep/dep }}$ mice to characterize the cell-specific effects of DHHC21 deficiency contributing to the reduced leucocyte-endothelial interactions. Wild-type leucocytes adhered normally to IL-1 $\beta$ activated wild-type ECs, but adhesion to Zdhhc21 dep/dep ECs was greatly attenuated. Interestingly, Zdhhc21dep/dep leucocyte adherence to wild-type ECs was unaffected, indicating the relative importance of endothelial DHHC21 in this process (Fig. $7 c, d$ ).

DHHC21 deficiency ameliorates endothelial barrier dysfunction. The vascular barrier function was also determined in $Z d h h c 21^{\text {dep/dep }}$ mice during inflammation. Upon LPS or burn-induced SIRS, less protein leakage from lung microvessels indicated by interstitial Evans Blue intensity was detected in $Z d h h c 21^{\text {dep/dep }}$ mice compared with that in Zdhhc21 $1^{+/+}$mice (Fig. 8a,b). Consistently, following histamine stimulation, increased FITC-albumin leakage was observed in mesenteric vessels of $Z d h h c 21^{+/+}$mice, but this response was significantly reduced in vessels of Zdhhc21 dep/dep mice (Fig. 8c,d).

The key role of endothelial DHHC21 in regulating barrier dysfunction was further confirmed in our in vitro inflammatory models. As shown in Fig. 8e, Zdhhc21 knockdown MLMVECs and Zdhhc21 dep/dep ECs exhibited attenuated hyperpermeability to FITC-albumin upon thrombin stimulation, and the endothelial hyperpermeability was nearly completely blocked in Zdhhc21 dep/dep ECs treated with 2-BP. Zdhhc21 dep/dep ECs also displayed significantly reduced transendothelial electric resistance (TER) response to thrombin (Fig. 8f); however overexpression of wild-type Zdhhc21 in Zdhhc21 dep/dep ECs restored their barrier responsiveness to thrombin (Fig. $8 \mathrm{~g}$ ).

Zdhhc21 dep/dep reduces PLC 11 palmitoylation and signalling. Since PLC $\beta 1$ was identified as a specific palmitoylation target

Figure 4 | Inflammatory stimuli increase PLC $\beta 1$ palmitoylation and its signaling activity. (a) Increased palmitoylation was detected in endothelial cells after stimulation with SIRS plasma or inflammatory stimuli. Representative images of palmitoylation in cells treated with vehicle, histamine $(10 \mu \mathrm{M}, 15$ min), thrombin $\left(10 \mathrm{U} \mathrm{ml}^{-1}, 30 \mathrm{~min}\right.$ ) or SIRS plasma (20\% dilution, $1 \mathrm{~h}$ ) in the absence or presence of 2-BP (pretreatment at $10 \mu \mathrm{M}$ ). Palmitoylated proteins were metabolically labelled with a palmitic acid analogue $\omega$-alkynyl palmitic acid (Alk-C16). Labelled proteins were visualized by further probing with fluorescent azide via Click chemistry reaction. Palmitoylated proteins are shown in green and nuclei blue. Scale bar, $30 \mu \mathrm{m}$. Bar graph shows quantification of total palmitoylation signal intensity. Results are from three independent experiments presented as mean \pm s.e.m. ${ }^{\star} P<0.05$ versus control + vehicle, ${ }^{\#} P<0.05$ versus stimulus + vehicle. $(\mathbf{b}, \mathbf{c})$ The levels of palmitoylated PLC $\beta 1$ in endothelial cells were determined using two different methods. (b) Acyl-biotin exchange. Whole cell lysates from thrombin $\left(10 \mathrm{U} \mathrm{ml}^{-1}\right)$ or vehicle treated $\mathrm{ECs}$, with or without 2-BP, were subject to acyl-biotin exchange to isolate palmitoylated proteins in the presence of hydroxylamine $\left(\mathrm{NH}_{2} \mathrm{OH}\right)$. The samples were then used in Western blotting for PLC $\beta 1$. Band intensity was quantified and normalized to control. Results represent three independent experiments. ${ }^{\star} P<0.05$ versus vehicle + control, ${ }^{\#} P<0.05$ versus vehicle + thrombin. (c) Pull-down of palmitoylated proteins and immunoblotting for PLC $\beta 1$. ECs were incubated with Alk-C16 overnight and then treated with histamine $(10 \mu \mathrm{M})$ or vehicle. Whole cell lysates were collected, and palmitoylated proteins were pulled down using Azide Agarose Resin via Click chemistry reaction. Palmitoylated protein samples were subject to Western blotting for PLC $\beta 1$. Band intensity was quantified and normalized to control group. Bar graph represents four independent experiments. ${ }^{\star} P<0.05$ versus vehicle. (d) IP3 levels in ECs subjected to histamine stimulation (10 $\mu$ M) with or without 2-BP $(10 \mu \mathrm{M})$. Bar graph represents mean \pm s.e.m. from three independent experiments. ${ }^{\star} P<0.05$ versus vehicle, ${ }^{\#} P<0.05$ versus

vehicle + histamine. 
a
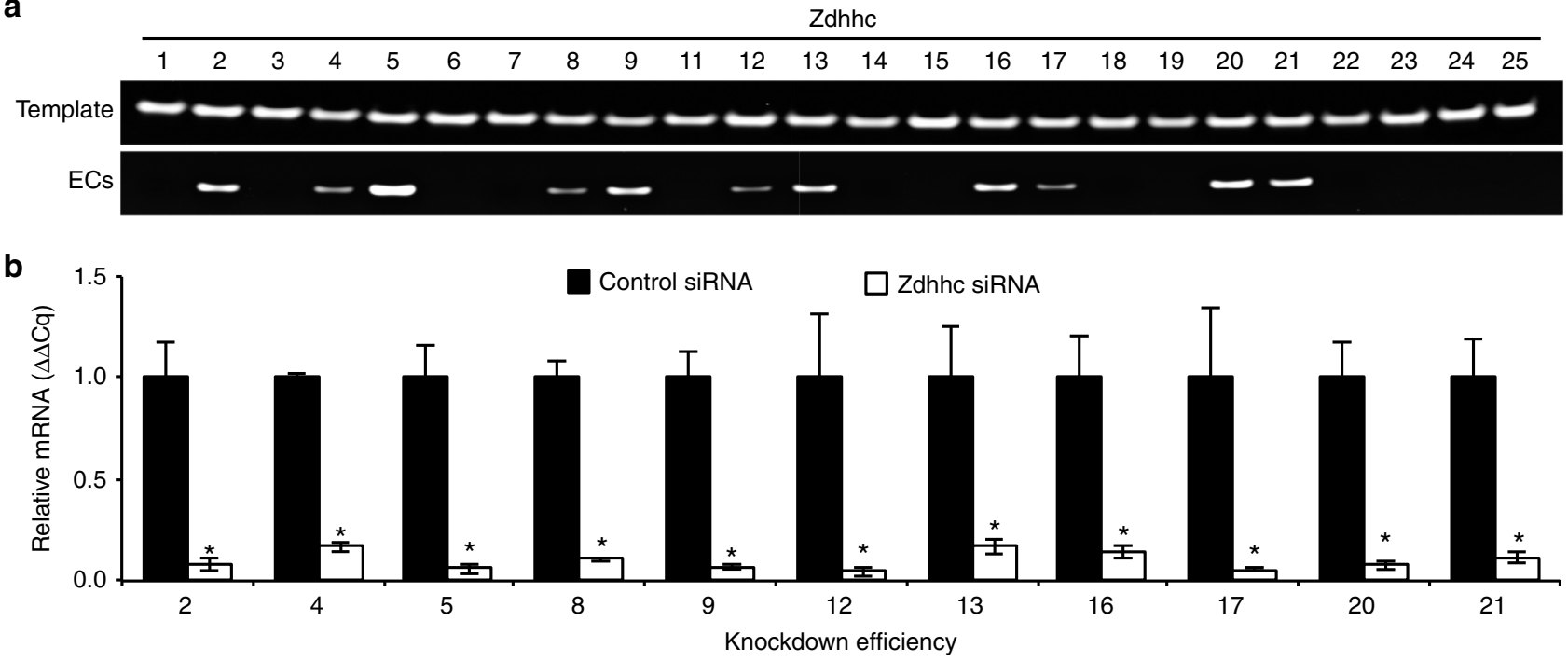

C

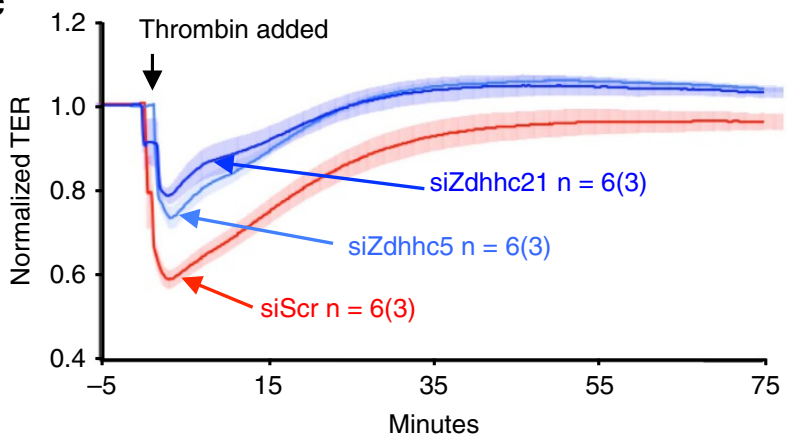

e

SiRNA Zdhhc

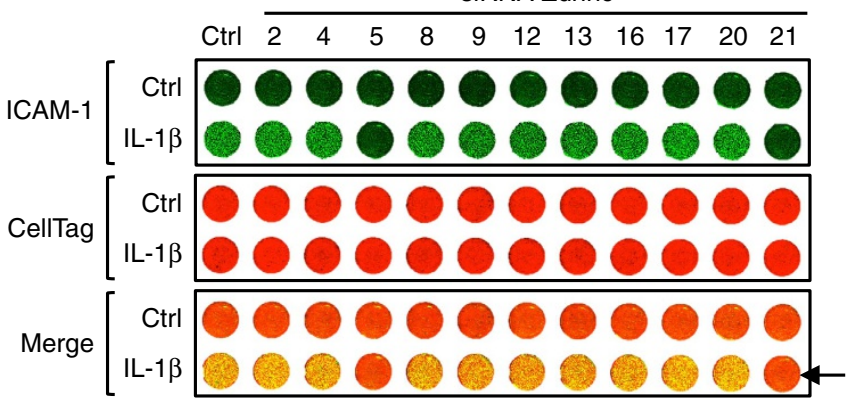

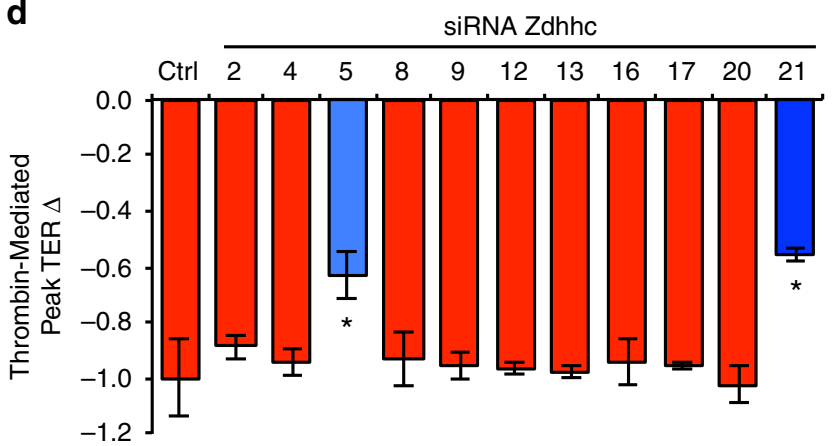

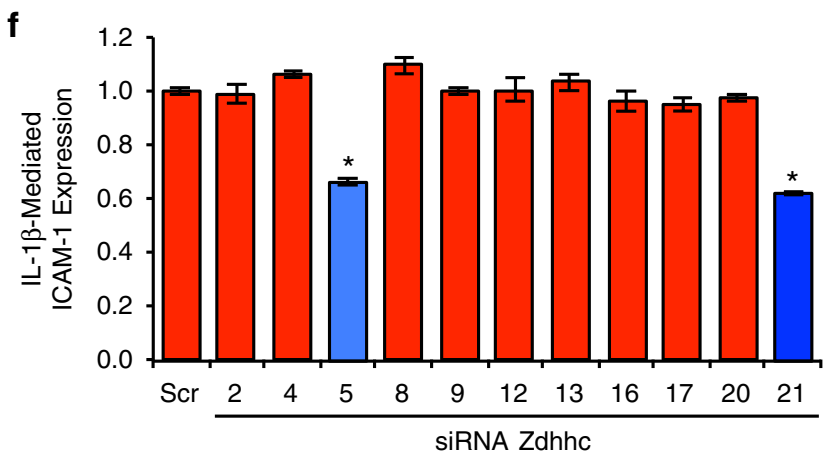

Figure 5 | Endothelial-expressing Zdhhcs and importance of DHHC5/21 in endothelial dysfunction. (a) Representative images from qualitative PCR analyses of 24 known murine Zdhhcs in primary MLMVECs that confirmed the expression of 11 Zdhhcs. cDNA template of each gene was used as a positive control. (b) Knockdown efficiency of the 11 Zdhhcs expressed in endothelial cells verified by RT-PCR, ${ }^{*} P<0.05$ versus control siRNA. (c,d) The effects of individual Zdhhc knockdown on thrombin-induced endothelial barrier dysfunction indicated by TER. (c) Representative TER tracings of Zdhhc5 and Zdhhc21 knockdown in response to thrombin $\left(10 \mathrm{U} \mathrm{ml}^{-1}\right)$. Solid line tracing represents the mean resistance, and shadow represents $\pm s$.e.m. $n=$ number of measurement; value in parentheses indicates number of independent experiments. (d) Quantification of peak TER reduction upon thrombin treatment in each Zdhhc knockdown group. Values were normalized to TER with control siRNA. Bar graph represents mean \pm s.e.m. from three independent experiments. ${ }^{\star} P<0.05$ versus control siRNA. (e,f) The effects of individual Zdhhc knockdown on IL-1 $\beta$-induced ICAM-1 expression on EC surface. MLMVECs in a 96 -well plate were stimulated with IL-1 $\left(100 \mathrm{ng} \mathrm{ml}^{-1}, 4 \mathrm{~h}\right)$. ICAM-1 surface expression was determined by on-cell western assay using Odyssey CLx Infrared Imaging System. (e) Representative images. CellTag staining was used for cell number normalization. Arrow indicates decreased ICAM-1 expression. (f) Quantification of ICAM-1 expression in Zdhhc knockdown ECs upon IL-1 $\beta$ stimulation. Results represent mean \pm s.e.m. from three independent experiments. ${ }^{\star} P<0.05$ versus control siRNA.

involved in inflammation, we hypothesized that PLC $\beta 1$ might serve as the substrate of DHHC21 that accounts for inflammation-mediated endothelial injuries. The effects of DHHC21 function on the PLC $\beta 1$ palmitoylation during inflammation were determined by resin-assisted capture, an assay that allows palmitoylated proteins to be cleaved by hydroxylamine $\left(\mathrm{NH}_{2} \mathrm{OH}\right)$ and captured with thiol-reactive Sepharose resin. Our data demonstrated that thrombin induced a detectable increase in PLC $\beta 1$ palmitoylation in $Z d h h c 21^{+/+}$ECs, which was attenuated in $Z d h h c 21^{\text {dep/dep }}$ ECs (Fig. 9a). Given that 
a
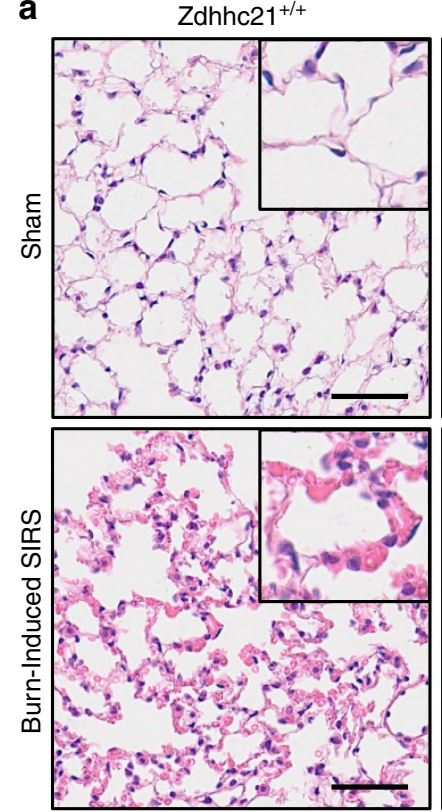

c

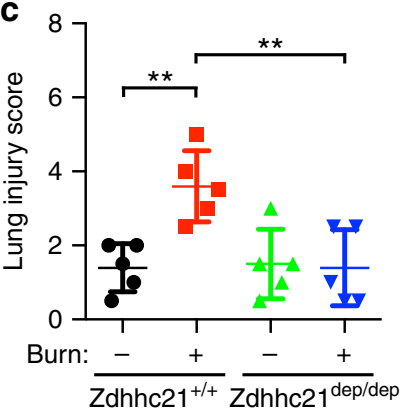

Zdhhc21 dep/dep
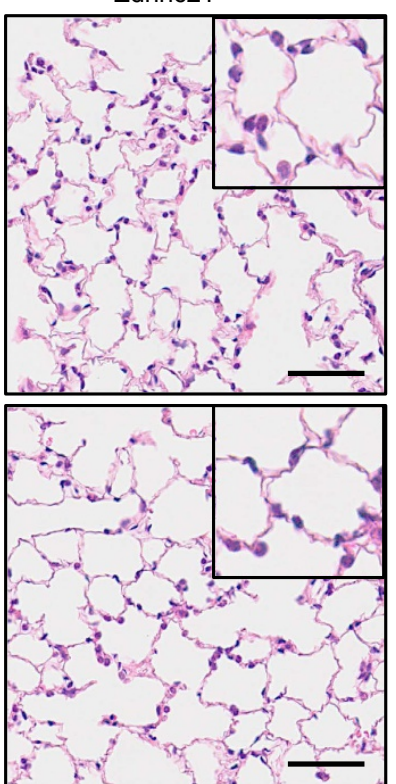

d

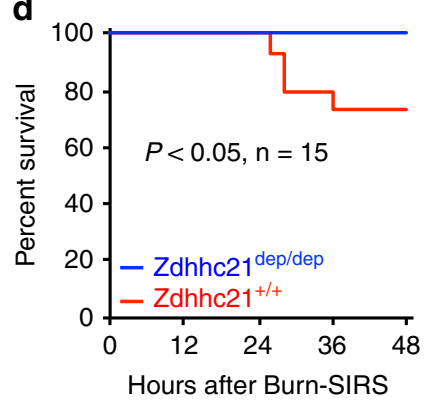

b
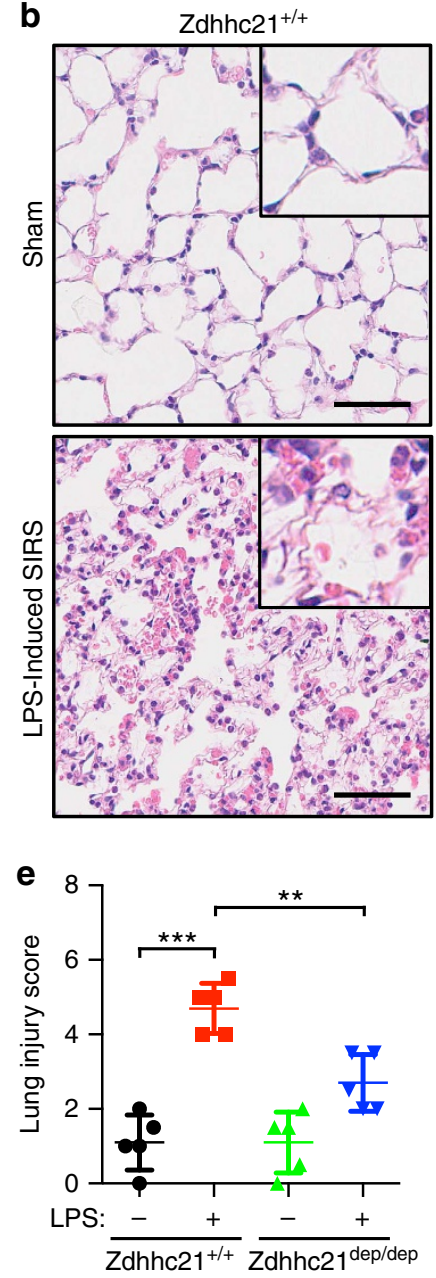
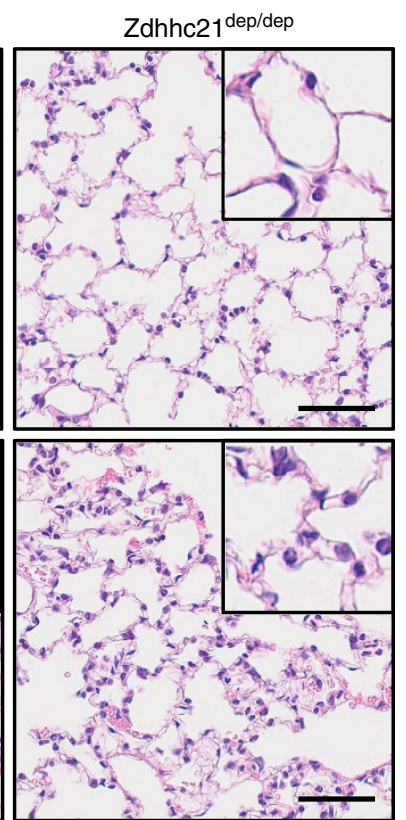

$\mathbf{f}$

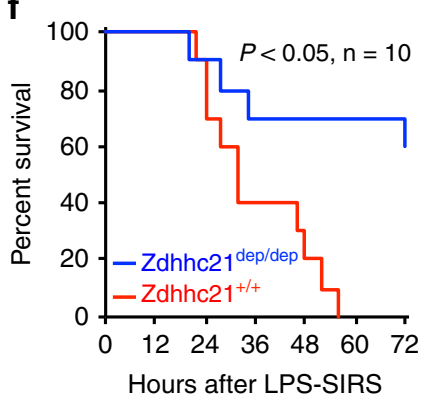

Figure 6 | Zdhhc21 dep/dep mice are resistant to SIRS-induced lung injury and mortality. (a,b) Representative images of lung tissues obtained from mice $24 \mathrm{~h}$ after thermal injury-induced (a) or LPS-induced SIRS (b) (five mice in each group). Scale bar, $50 \mu \mathrm{m}$. (c) Lung histology injury scores in thermal injury-induced SIRS. Results represent mean \pm s.e.m. from five mice. ${ }^{\star \star} P<0.01$. (d) Survival rates in mice subjected to thermal injury ( $n=15$ mice). (e) Lung histology injury scores in LPS-induced SIRS. Results represent mean \pm s.e.m. from five mice. ${ }^{\star \star} P<0.01$, ${ }^{\star \star \star} P<0.001$. (f) Survival rates in mice subjected to LPS challenge ( $n=10$ mice).

palmitic acid attachment can alter protein hydrophobicity and membrane association ${ }^{23}$, we then compared membrane localization of PLC $\beta 1$ between $Z d h h c 21^{+/+}$and $Z d h h c 21^{\text {dep/dep }}$ ECs. However, no significant difference of PLC $\beta 1$ plasma membrane localization was found between these two cells under baseline or inflammatory conditions (Fig. 9b).

Thrombin-induced increased membrane localization of PKC, a downstream effector of PLC $\beta 1$ signalling known to translocate to cell membranes upon activation, was inhibited in DHHC21 deficient ECs (Fig. 9b), supporting the involvement of DHHC21induced PLC $\beta 1$ palmitoylation in PLC $\beta 1$ signalling activation. Two other effectors of PLC $\beta 1$, namely IP3 and intracellular calcium, were also evaluated as the indication of PLC $\beta 1$ downstream signalling activation. The level of IP3 was increased by thrombin stimulation, which was greatly attenuated in Zdhhc21 dep/dep ECs (Fig. 9c). Consistently, thrombin-elicited intracellular calcium spike was diminished in $Z d h h c 21^{\text {dep/dep }}$ MLMVECs compared with Zdhhc21 ${ }^{+/+}$ECs (Fig. 9d,e).

DHHC21-PLC $\beta 1$ pathway in endothelial barrier dysfunction. The critical role of PLC $\beta 1$ in mediating endothelial dysfunction is supported by the data that knockdown of PLC $\beta 1$ in $Z d h h c 21^{+/+}$ ECs led to a significantly attenuated TER response to thrombin
(Fig. 10a,c). Furthermore, in an in silico analysis using the CSS palm palmitoylation algorithm ${ }^{38}$, only cysteine residue 17 of PLC $\beta 1$, with a high CSS-palm score of 27 , was above the medium threshold and predicted to be palmitoylated. We thus created a mutant PLC $\beta 1$ by replacing Cys17 with serine to disable palmitoylation at this site. Comparative analyses were performed in Zdhhc21 $1^{+/+}$or Zdhhc21 dep/dep ECs overexpressing the mutant or wild-type PLC $\beta 1$ (Fig. 10b,d-f). The results indicated that overexpression of wild-type PLC $\beta 1$ in Zdhhc21 $1^{+/+}$ECs augmented TER reduction upon thrombin stimulation (Fig. 10d), whereas overexpression of C17S mutant PLC $\beta 1$ exerted no additional barrier dysfunction (Fig. 10e). Moreover, overexpression of wild-type PLC $\beta 1$ in Zdhhc21 ${ }^{\text {dep/dep }}$ ECs failed to augment thrombin-induced barrier dysfunction (Fig. 10f). These data suggested the key role of DHHC21-catalysed PLC $\beta 1$ palmitoylation in mediating inflammation-induced endothelial barrier dysfunction.

\section{Discussion}

The present study demonstrates a novel function of palmitoyl acyltransferases in mediating endothelial dysfunction during inflammation. We employed multiple in vivo, ex vivo and in vitro models relevant to SIRS, including trauma, endotoxemia 
a

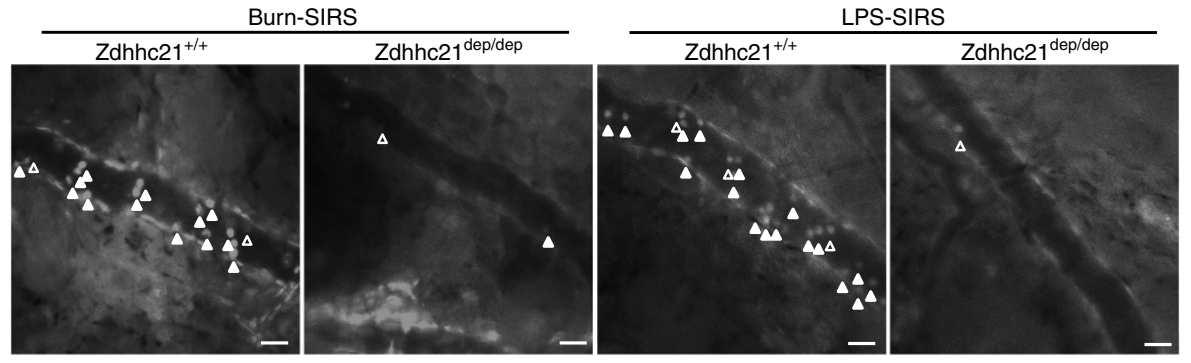

b

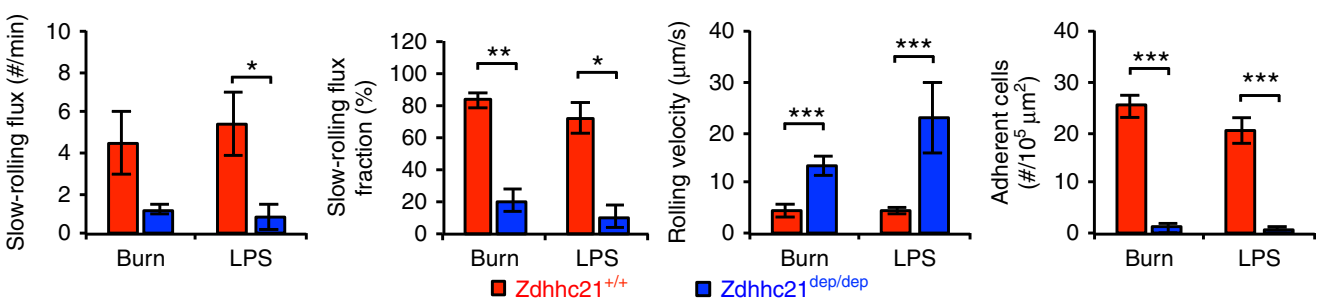

C
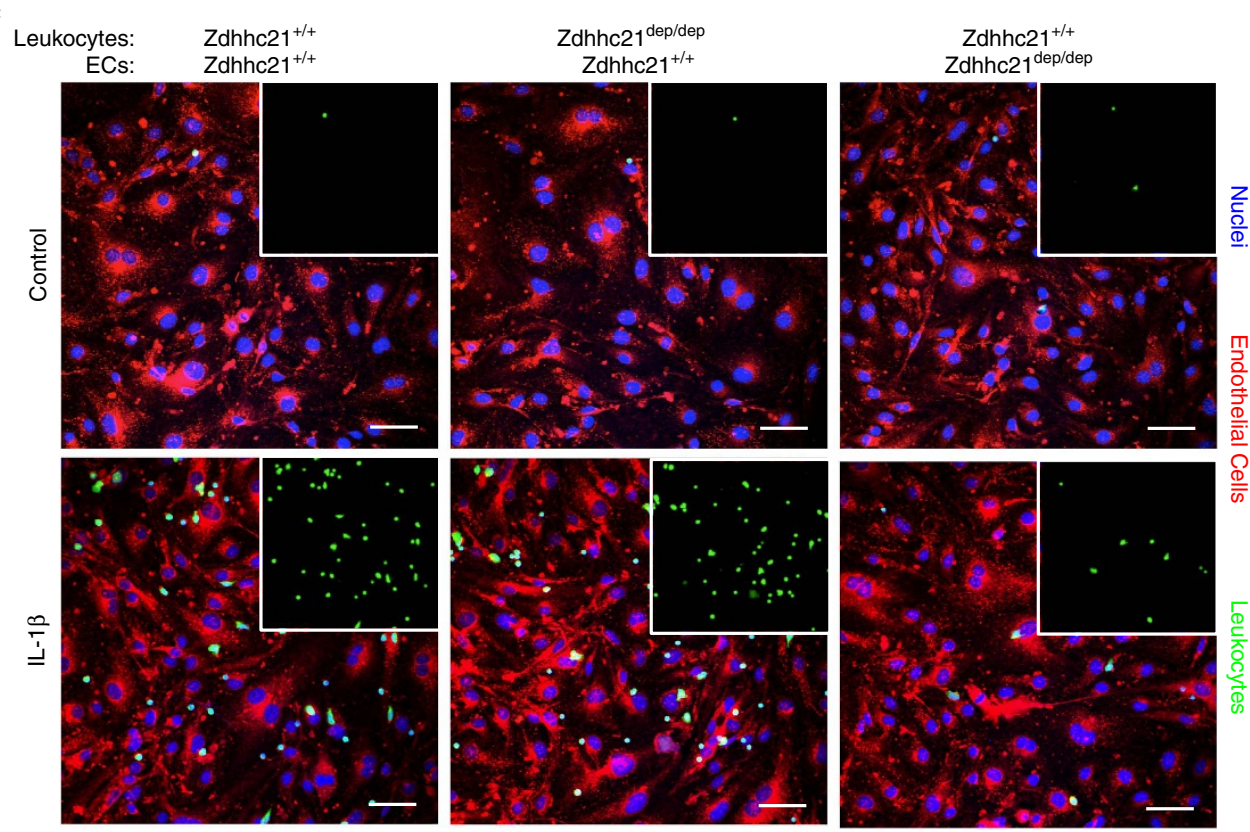

d
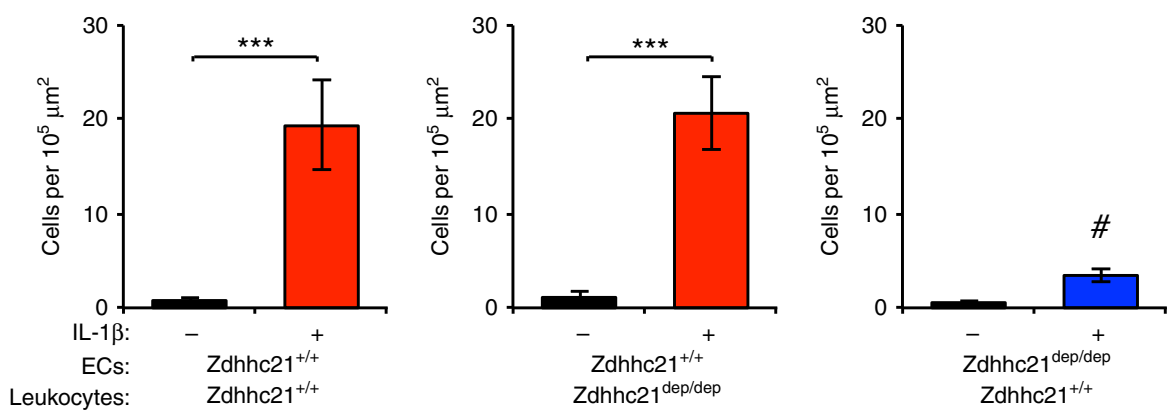

Figure 7 | DHHC21 deficiency attenuates leucocyte-endothelial adhesion during inflammation. (a) Representative images of intravital microscopic analyses of microvessels in mouse ears during burn or LPS challenge. Scale bars, $50 \mu \mathrm{m}$. Solid arrowheads point to adherent leucocytes; open arrowheads point to slow-rolling leucocytes. (b) Quantification of leucocyte slow-rolling flux, slow-rolling fraction, rolling velocity and adhesion in $Z d h h c 21^{+} /+{ }^{2}$ and $Z d h h c 21^{d e p / d e p}$ mice $4 \mathrm{~h}$ postburn or LPS. Results represent mean \pm s.e.m. from six mice. ${ }^{\star} P<0.05,{ }^{\star \star} P<0.01,{ }^{\star \star \star} P<0.001$. (c,d) Comparative analysis of the leucocyte adhesion in endothelial versus leucocytic $Z d h h c 21^{d e p} /$ dep using a chimeric approach. Leucocytes were isolated from either $Z d h h c 21^{+} /+$or

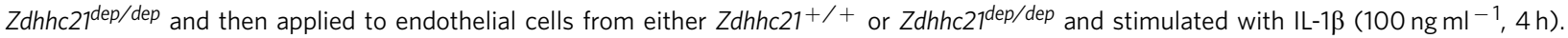

(c) Representative confocal images of adherent leucocytes. Embedded images show leucocyte channel alone. Nuclei were stained with DAPI. Scale bars, $100 \mu \mathrm{m}$. (d) Quantification of adherent leucocytes shows that endothelial cells from Zdhhc21dep/dep displayed marked resistance to leukocyte adhesion, whereas leucocytes from these mice did not show altered adhesiveness. Results present mean \pm s.e.m. from three independent experiments. ${ }^{\star \star \star} P<0.001$ versus unstimulated. ${ }^{\#} P<0.05$ versus $\mathrm{IL}-1 \beta+Z$ dhhc $21+/+\mathrm{EC}+Z$ dhhc $21+/+$ leukocyte. 
a

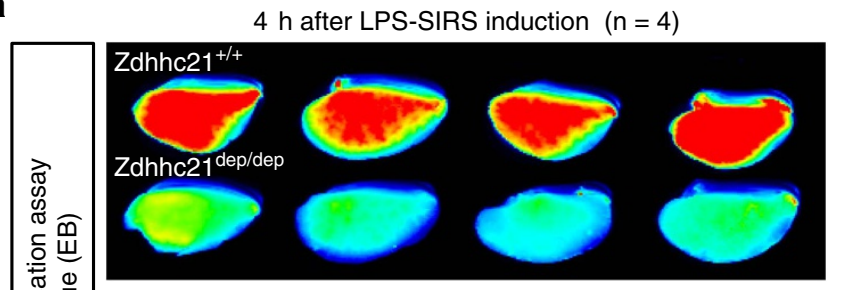

$4 \mathrm{~h}$ after burn-SIRS induction $(\mathrm{n}=4)$

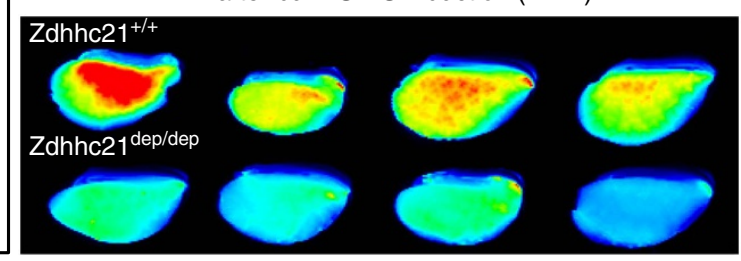

b

Normalized LPS-SIRS-induced EB extravasation

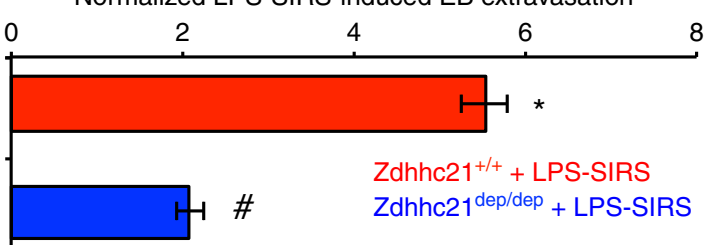

Normalized burn-SIRS-induced EB extravasation

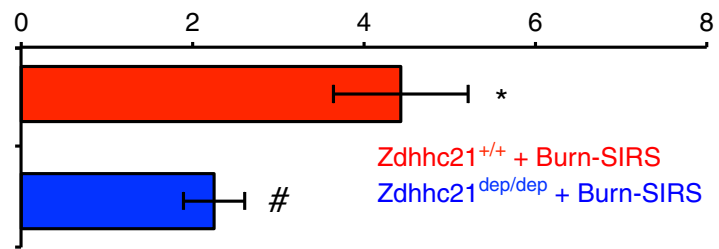

C
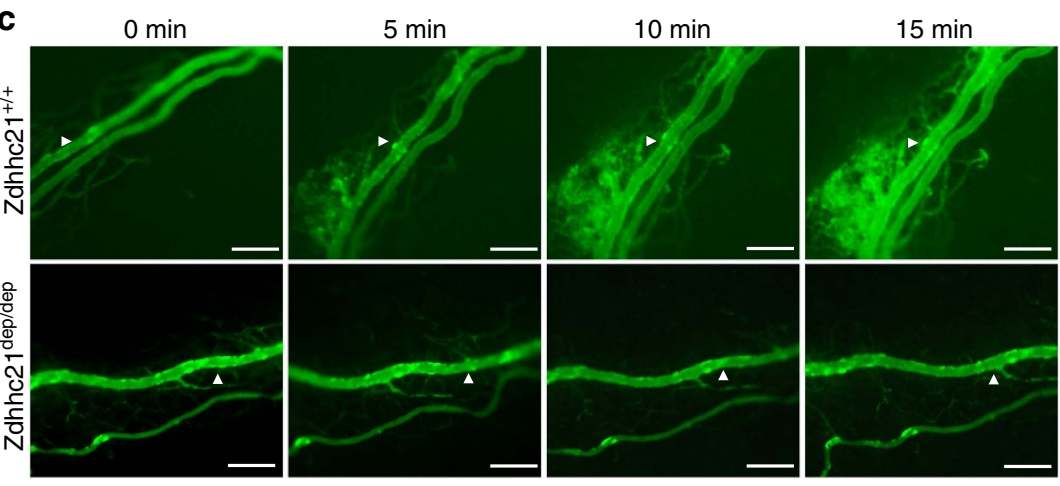

d

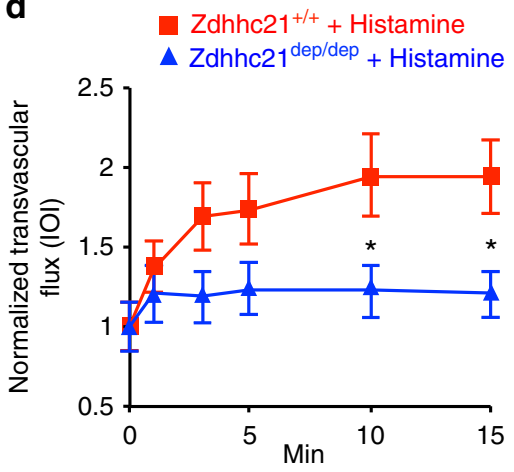

9

f

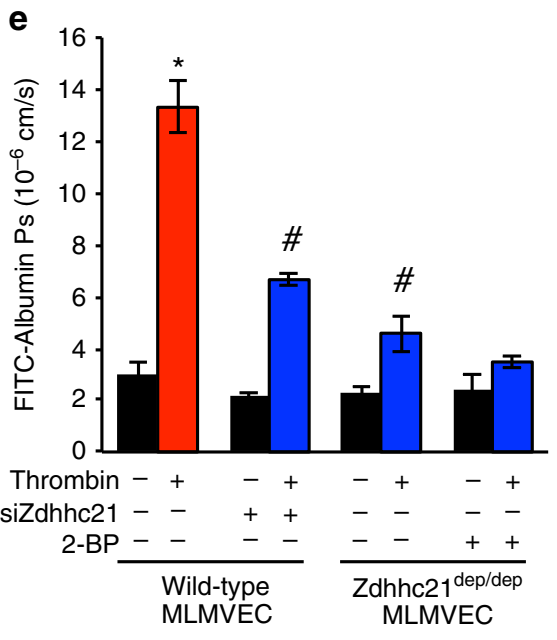

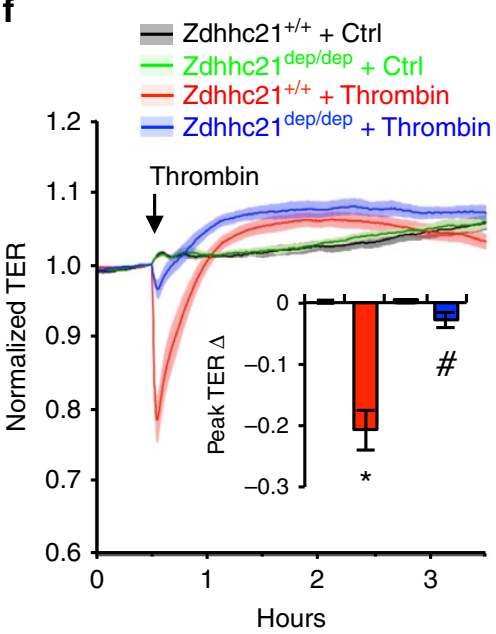
- Zdhhc21 ${ }^{\text {dep/dep }}+$ pCMV6-Empty
- Zdhhc21

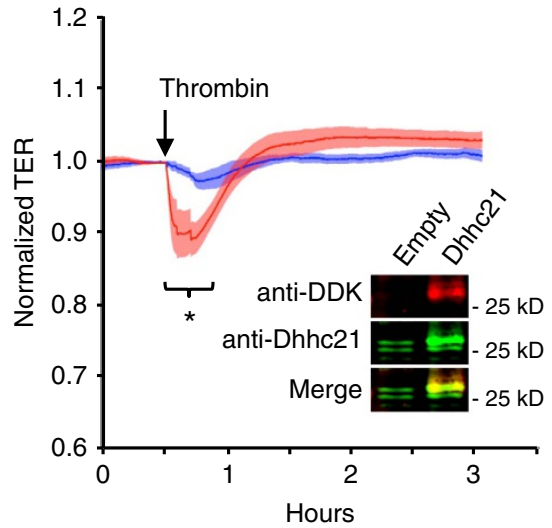

Figure 8 | DHHC21 deficiency prevents inflammation-mediated vascular barrier dysfunction. (a,b) Following LPS or thermal injury, Zdhhc21dep/dep mice displayed decreased plasma protein extravasation in the lungs. (a) Images of four replicates used to qualitatively demonstrate SIRS-induced Evans Blue extravasation in whole left lung lobes (signal intensity low = blue, high =red). (b) Quantitative results of Evans Blue extravasation assays. Values were normalized to $Z d h h c 21^{+/+}$mice receiving sham operation. Results represent mean \pm s.e.m. from four independent experiments. ${ }^{\star} P<0.05$ versus Zdhhc $21^{+/+}+$sham, ${ }^{\#} P<0.05$ versus Zdhhc $21^{+/+}+$SIRS. (c,d) Histamine-induced transvascular flux of FITC-albumin from mesenteric microvessels. (c) Representative images at 0, 5, 10 and $15 \mathrm{~min}$ after histamine application. Scale bars, $100 \mu \mathrm{m}$. Arrowheads indicate the observed microvessel. (d) Quantification of plasma transvascular flux. For each genotype, value was normalized to its own $t=0$ min. Results represent mean \pm s.e.m. from six mice. ${ }^{\star} P<0.05$ versus $Z d h h c 21^{+/+}+$histamine. (e) The effects of Zdhhc21 knockdown or loss-of-function on endothelial permeability to FITC-albumin with or without 2-BP $(100 \mu \mathrm{M})$. Thrombin $\left(10 \mathrm{U} \mathrm{ml}^{-1}\right)$ was applied to MLMVEC monolayers and their permeability was calculated based on albumin transendothelial diffusion rate. Bar graph represents mean \pm s.e.m. at $n \geq 3$. ${ }^{\star} P<0.05$ versus $Z d h h c 21+/+E C+$ vehicle, ${ }^{\#} P<0.05$ versus $Z d h h c 21+/+$ $\mathrm{EC}+$ thrombin. (f) Dynamic changes of endothelial barrier resistance to thrombin $\left(10 \mathrm{U} \mathrm{ml}{ }^{-1}\right)$ in MLMVECs isolated from Zdhhc $21^{+/}++$and $Z d h h c 21^{d e p} /$ dep mice. TER value of each time point is normalized to baseline. Solid line tracing represents the mean resistance, and shadow represents standard error. Embedded graph shows maximum TER changes. Bar graph represents mean \pm s.e.m. ${ }^{\star} P<0.05$ versus $Z$ dhhc $21^{+/}+\mathrm{EC}+$ vehicle , ${ }^{\#} P<0.05$ versus Zdhhc $21^{+/+} \mathrm{EC}+$ thrombin. (g) Blunted TER response to thrombin $\left(10 \mathrm{U} \mathrm{ml}{ }^{-1}\right.$ ) was partially rescued in cells overexpressing wild-type DHHC21. Zdhhc21 (DDK tagged) or empty vector was overexpressed in Zdhhc21dep/dep ECs. Results represent mean resistance \pm s.e.m. The efficiency of Zdhhc21 overexpression was verified by Western blotting using anti-DDK tag and anti-DHHC21 antibody (Embedded graph). 
a

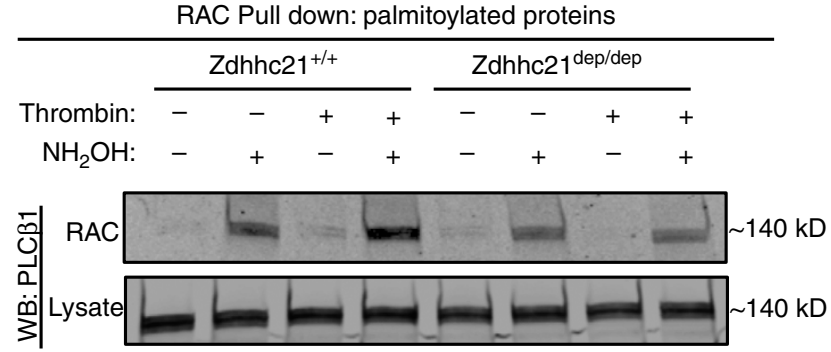

b

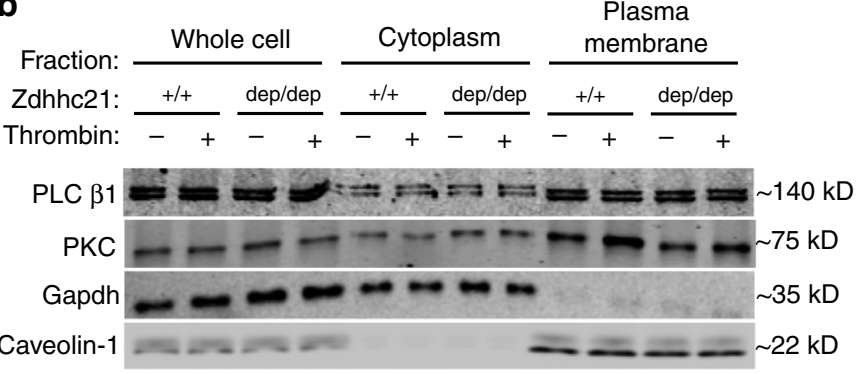

C

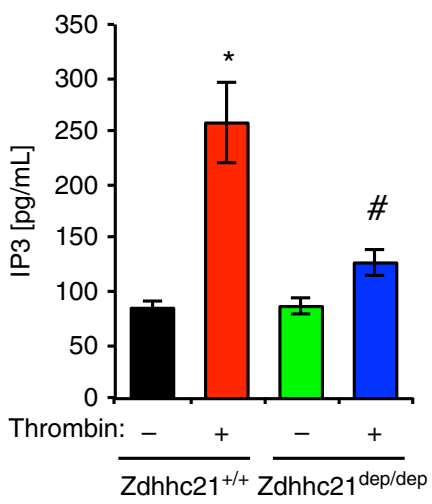

d

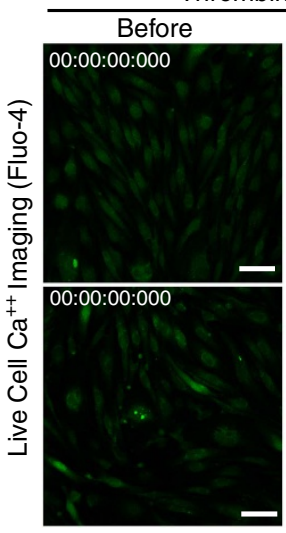

Thrombin stimulus

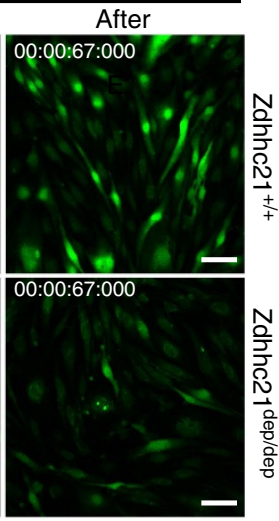

e

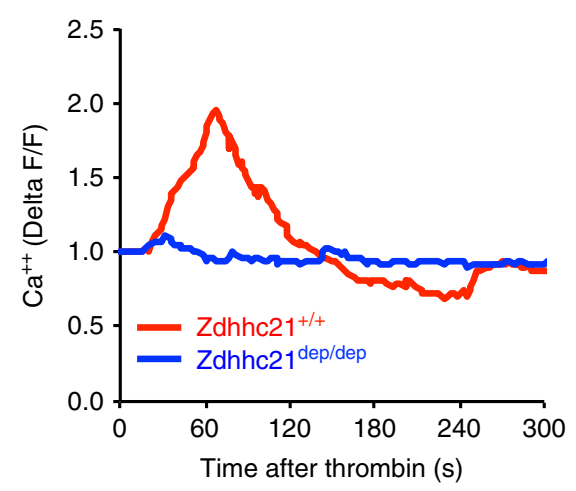

Figure 9 | DHHC21 deficiency reduces inflammation-induced PLC $\beta 1$ palmitoylation and signaling activity. (a) The level of palmitoylated PLC $\beta 1$ in Zdhhc $21^{+/+}$and Zdhhc2 $21^{\text {dep} / d e p ~ E C s ~ w i t h ~ o r ~ w i t h o u t ~ t h r o m b i n ~}\left(10 \mathrm{U} \mathrm{ml}{ }^{-1}\right)$ was determined using resin-assisted capture. Palmitoylated proteins in whole cell lysate were isolated by thiol-reactive sepharose resin in the presence of hydroxylamine $\left(\mathrm{NH}_{2} \mathrm{OH}\right)$ and then used for immunoblotting with anti-PLC $\beta 1$. Blot is representative of four independent experiments. (b) Membranous and cytosolic fractionation assay showing the subcellular distribution of PLC $\beta 1$ and its downstream signal PKC in Zdhhc21 $1^{+/+}$and Zdhhc27dep/dep ECs with or without thrombin $\left(10 \mathrm{U} \mathrm{ml}^{-1}\right)$. Images are representatives of three independent experiments. Gapdh and caveolin-1 were used as internal loading controls (Gapdh for whole cell and cytoplasm fraction, caveolin-1 for plasma membrane fraction). (c) IP3 levels indicative of PLC $\beta 1$ signaling activity in Zdhhc $21^{+/+}$and Zdhhc $21^{\text {dep} / \text { dep }}$ ECs subjected to thrombin (10 U ml ${ }^{-1}$ ) stimulation. Bar graph represents mean \pm s.e.m. from three independent experiments. ${ }^{\star} P<0.05$ versus $Z$ dhhc $21^{+} /+E C+$ control, ${ }^{\#} P<0.05$ versus Zdhhc $21^{+/+}$EC + thrombin. (d,e) Intracellular calcium spike indicative of PLC 31 activation in ECs isolated from Zdhhc $21^{+/+}$or Zdhhc2 2 dep/dep . Data represents three independent experiments. (d) Representative images of live EC monolayers labelled with the calcium indicator Fluo-4 before and after thrombin stimulation. (e) Representative tracings of intracellular calcium concentration.

and inflammatory stimuli. Our data reveal several new findings: (1) PAT inhibition attenuates inflammation-induced endothelial barrier dysfunction, microvascular leakage and leucocyte adhesion; (2) the cellular processes underlying PAT-induced injury involve endothelial cell-cell junction hyperpermeability and increased expression of ICAM-1; (3) 11 DHHC-PATs are detected to be expressed in vascular endothelium: DHHC2, 4, 5, $8,9,12,13,16,17,20$ and 21 , of which DHHC5 and 21 are required for barrier response to inflammatory stimulation; (4) mice with DHHC21 function deficiency are resistant to plasma leakage and leucocyte infiltration; they also display attenuated lung pathology and improved survival following traumatic or septic challenge; (5) DHHC21 deficiency confers protection against inflammatory injury via an endothelialdependent pathway; and (6) DHHC21-mediated PLC $\beta 1$ palmitoylation and activation of its downstream signalling play an important role in mediating endothelial dysfunction during inflammation.

Remarkable heterogeneity exists in PATs with respect to their tissue/cell distributions and $\mathrm{N}$ - or C-terminal extensions ${ }^{23,36}$. Comparing mRNAs from multiple tissues, Ohno et al. showed that $Z d h h c s$ 4, 5, 7, 8, 10,12, 13, 17 and 22 were ubiquitously expressed, while others were highly tissue-specific ${ }^{36}$. For example, $Z d h h c 11$ was found only in testis, Zdhhc19 in testis, thymus and small intestine, and $Z d h h c 21$ was found in multiple tissues including blood vessels, but is absent in leucocytes ${ }^{33,36}$. Within this context, although Zdhhcs 2, 3, 7, 8 and 21 have been identified in human umbilical vein endothelial cells ${ }^{39}$, our experiments are the first to screen endothelial cells from different vascular beds for expression of all 24 Zdhhcs. We identified the presence of Zdhhcs 2, 4, 5, 8, 9, 12, 13, 16, 17, 20 and 21 in mouse lung microvascular endothelial cells, cells frequently implicated in acute systemic inflammation and commonly used as a clinically relevant cell model. While the absence of $Z$ dhhcs 3 and 7 in our findings is not in perfect agreement with a previous report ${ }^{39}$, the discrepancy could be attributed to organ or species heterogeneity. Interestingly, $Z d h h c 21$ appears to be ubiquitous among endothelial cells from different vascular beds and between species, supporting its common involvement in the circulatory system. This is important because different DHHC-PATs may contribute to different cellular or pathological processes. For example, DHHC8 has been linked to schizophrenia ${ }^{30}$, DHHC9 to intellectual disability ${ }^{40}$, DHHC17 to type 1 diabetes and Huntington's disease ${ }^{41}$, and DHHC2, 9, 11 and 17 to cancer ${ }^{42}$. We believe our study is the first to demonstrate the pathophysiological significance of DHHC21 in inflammatory injury.

Proteins spanning from signalling molecules to membrane proteins have been shown, or predicted by proteomics analyses, to be palmitoylated in response to extracellular or intracellular stimulation ${ }^{23,43}$. Unlike other fatty acid modifications, S-palmitoylation is reversible as depalmitoylation can be catalysed 
by acyl protein thioesterases (APTs) ${ }^{20}$. The multi-functionality and reversibility of palmitoylation has attracted rising interests in drug research. Inhibitors of palmitoylating enzymes have been developed and tested as therapies for cancer and autoimmune disease. Among the PAT inhibitors available in the market, 2-BP is best studied and most commonly used because of its relative selectivity and high potency toward PATs with minimal toxicity $^{44-46}$. Cell culture experiments with 2-BP demonstrated considerable tolerability in endothelial cells, while 2-BP simultaneously prevented glucose-mediated toxicity ${ }^{47}$. There are also reports on its short-term use as a tracer for in vivo experiments ${ }^{48}$. In our study, we did not detect any obvious morphological or functional changes in endothelial cells incubated with 2-BP, and administration of the drug in animals did not cause mortality or significant abnormalities in circulatory function. In view of its potent protective effect on endothelial a
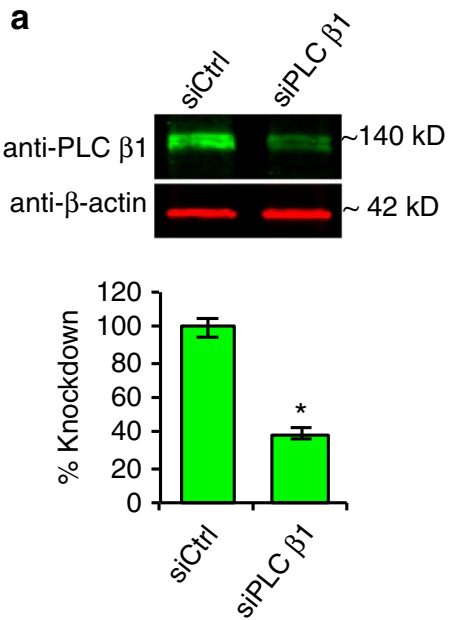

b

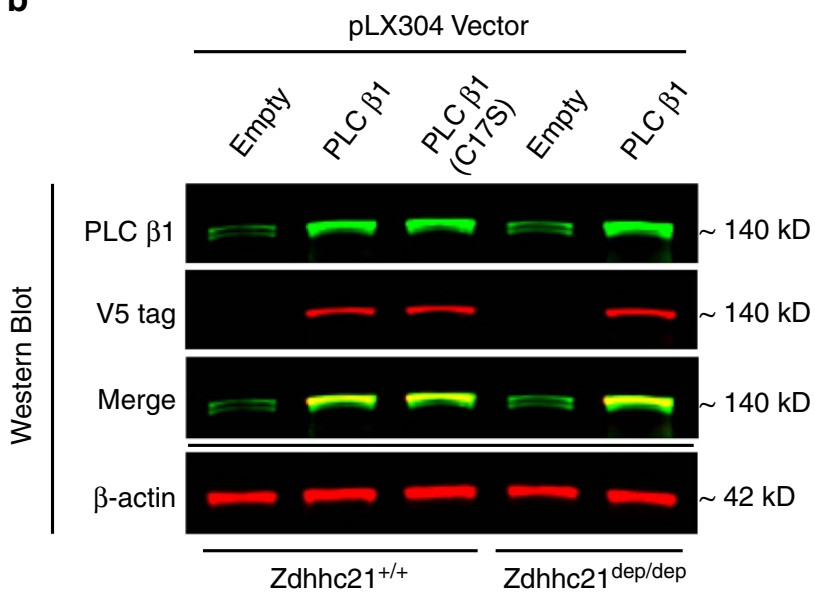

C - siCtrl + Vehicle $\quad$ siCtrl + Thrombin
siPLC $\beta 1+$ Vehicle
siPLC $\beta 1+$ Thrombin

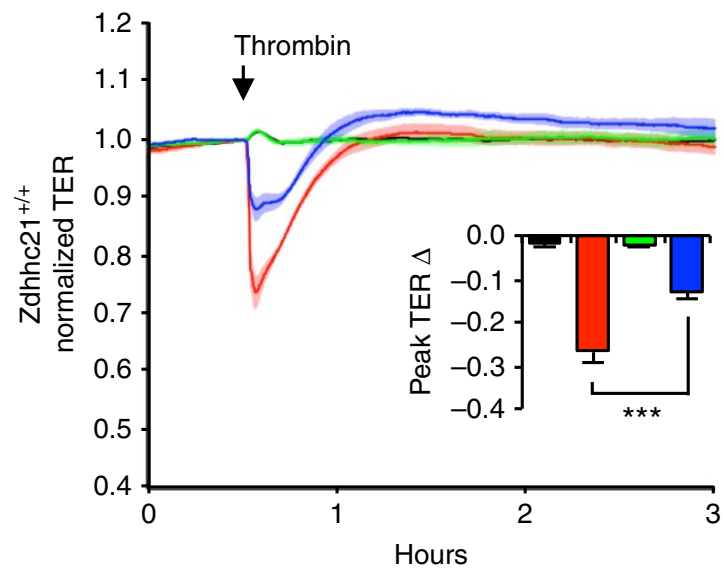

e
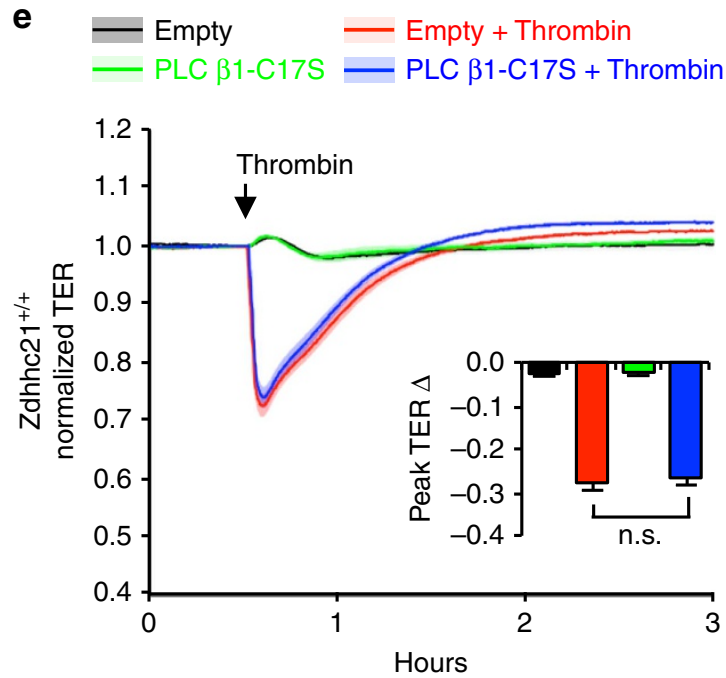

d

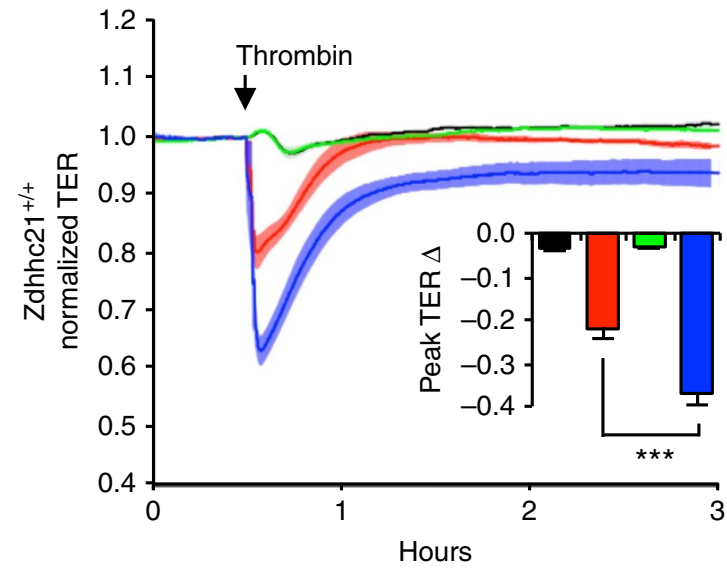

f

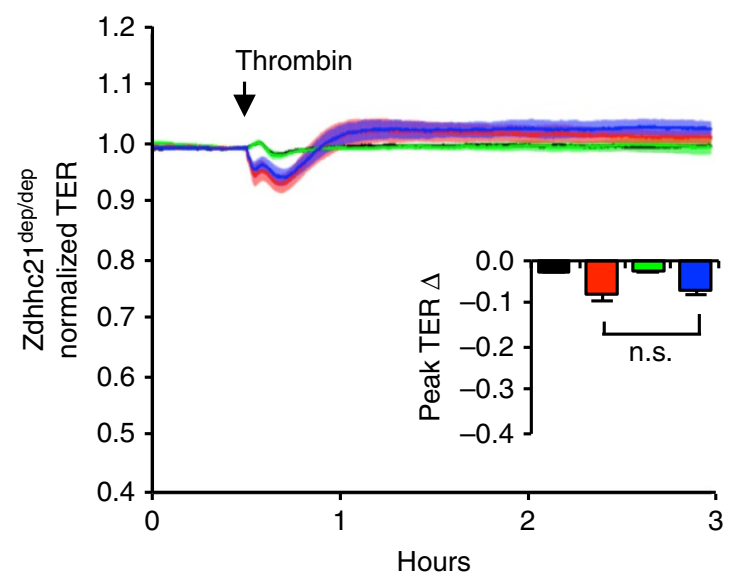


barriers without obvious adverse actions in vivo, the drug may have therapeutic potential as an anti-inflammation adjuvant. However, we do acknowledge the limitation of the pharmacological approach, as 2-BP might exert off-target effects that are not specific to vascular tissues. The drug could also affect other signalling processes than palmitoylation, or inhibit enzymes such as APTs and PPAR $\gamma^{49}$. Although we conducted time-course and dose-response studies with 2-BP and compared its effects with other palmitoylation-altering agents including 2-hydroxymyristate and palmostatin-B, further studies are warranted to establish the pharmacokinetics and pharmacodynamics of these drugs under specific disease conditions. Nevertheless, the primary purpose of the current study was to provide proof-of-principle for the involvement of PATs in inflammatory signal transduction.

A particularly novel aspect of our study is the demonstration that DHHC21 function deficiency confers protection against endothelial injury during inflammation. The $Z d h h c 21^{\text {dep/dep }}$ is a genetically altered mouse model resulting from 3-base pair deletion in the $Z d h h c 21$ exon rendering its loss-of-function in catalysing palmitoylation. Compared with knockouts, this model offers a unique opportunity to specifically study its enzymatic activity so that pharmacological or molecular tools can be designed to manipulate its function without demolishing its expression. The mouse phenotype is characterized by depilation and heavily pigmented greasy skin ${ }^{37}$. In our experiments, these mice were born at a normal gestational rate, were weaned into adulthood with no complications, and did not display obvious abnormalities in their basal cardiopulmonary or microcirculatory function. A more recent phenotypic characterization revealed attenuated $\alpha 1$ adrenergic-dependent vasomotor reactivity to phenylephrine and transient hypotension; however, no fluid imbalance, renal impairment or gross histological differences in the heart or kidney were found 33 . Importantly, endothelialdependent vasodilation was unaffected, making the Zdhhc2 $1^{\text {dep/ }}$ dep model advantageous for studying barrier-specific regulation of fluid dynamics with minimized confounding variables from hemodynamics. We chose to focus on Zdhhc21dep/dep in this study because DHHC21 was one of the only two DHHCs required for endothelial hyperpermeability, as verified in our functional screening analysis using individual gene knockdown. Further, the absence of DHHC21 in leucocytes ${ }^{36}$ serves as a tool for distinguishing endothelial-dependent pathways in barrier regulation and leucocyte recruitment, processes regulated by molecules present in both cell types. It is noteworthy that DHHC5 was also identified to be present in endothelial cells and silencing its gene was able to attenuate endothelial barrier response. However, DHHC5 is ubiquitously expressed in circulating and parenchymal cells ${ }^{36}$, and relatively limited information is accessible regarding the cardiovascular phenotypes of $Z d h h c 5$ knockout mice.

The precise molecular mechanisms by which DHHC21 loss-of-function confers protection against aberrant endothelial activation require further studies. Given the recent report about low blood pressure in $Z d h h c 21^{\text {dep/dep }}$ mice $^{33}$, we do not rule out the possibility that the observed protection was related to limited access of inflammatory mediators to important tissues under a relatively low perfusion pressure. However, our in vitro experiments using cells isolated from these mice suggest a direct effect of DHHC21 on endothelial junction and ICAM-1 expression. This is further supported by the fact that silencing DHHC21 produced similar protection as DHHC21 function deficiency. While the barrier effect of gene silencing appears small, it could be due to some residual expression of the enzyme. Alternatively, these relatively modest molecular reactions could translate into a significant phenotypic change in vivo altering microvascular transport and leucocyte recruitment in important organs. Endothelial barrier opening can further promote leucocyte transmigration thereby exacerbating inflammatory injury. Within this context, our imaging analysis of endothelial junctions showed that VE-cadherin staining became thinner and disrupted upon inflammatory stimulation, consistent with the notion that both junction protein degradation and conformational changes contribute to paracellular hyperpermeability.

The role of DHHC21 in regulating PLC $\beta 1$ palmitoylation and activity is supported by the data that DHHC21 deficiency attenuates inflammation-stimulated PLC $\beta 1$ palmitoylation coupled with activation of its downstream signalling as indicated by IP3 production, intracellular calcium spike and PKC membrane translocation. Moreover, endothelial cells overexpressing wild-type PLC $\beta 1$ displayed significantly augmented barrier dysfunction response to stimulation, whereas DHHC21 deficient cells or cells overexpressing PLC $\beta 1$ C17 mutant did not show such a phenotype, further indicating PLC $\beta 1$ palmitoylation as a target of DHHC21. Consistent with these mechanistic experiments, our proteomics analysis combining $\mathrm{ABE}$ with mass spectrometry identified a number of endothelial proteins undergoing palmitoylation upon stimulation by SIRS plasma, including PLCs and proteins related to the GPCR signalling pathway. How palmitoylation activates these signalling molecules remains an interesting question. Since palmitic acid attachment can alter the hydrophobicity of a protein thereby increasing its association with cell membranes ${ }^{23}$ where several DHHCs are located $^{20,24,29,36}$, we initially hypothesized that palmitoylation might promote PLC $\beta 1$ recruitment to the cell membrane. To our surprise, however, we did not observe any significant difference of PLC $\beta 1$ distribution in the cytosolic and membranous fractions of

Figure 10 | DHHC21-mediated PLC $\beta 1$ palmitoylation contributes to barrier dysfunction in inflammation. Molecular manipulations of DHHC21 or PLC $\beta 1$ via knockdown and site-specific mutagenesis indicate the involvement of DHHC21-PLC $\beta 1$ palmitoylation in endothelial barrier response. (a) Verification of PLC $\beta 1$ siRNA knockdown by Western blotting. $\beta$-actin serves as loading control. Results represent mean \pm s.e.m. from three independent experiments. ${ }^{\star} P<0.05$ versus control siRNA. (b) Verification of wild-type PLC 1 or $\mathrm{C} 17 \mathrm{~S}$ mutant PLC 11 (V5 tagged) overexpression in Zdhhc $21+/+$ or Zdhhc21dep/dep ECs. PLC 11 C17S mutant was created by site-specific mutagenesis at Cys17, the highly predicted palmitoylation site. Empty pLX304 vector serves as vector control. $\beta$-actin serves as loading control. (c) Dynamic recording of TER responses to thrombin $\left(10 \mathrm{U} \mathrm{ml}^{-1}\right)$ in PLC $\beta 1$ knockdown ECs. Solid line tracing represents the mean resistance, and shadow represents \pm s.e.m. Embedded bar graph shows peak TER changes and presented as mean \pm s.e.m. from three independent experiments. ${ }^{\star \star \star} P<0.001$. (d) The effect of overexpressing wild-type PLC $\beta 1$ on TER responses to thrombin $\left(10 \mathrm{U} \mathrm{ml}{ }^{-1}\right)$ in $Z d h h c 21^{+/}+E^{2}$. Solid line tracing represents the mean resistance, and shadow represents \pm s.e.m. Embedded bar graph shows peak TER value changes. Bar graph represents mean \pm s.e.m. from three independent experiments. ${ }^{\star \star \star} P<0.001$. (e) The effect of overexpressing C17S mutant PLC $\beta 1$ (palmitoylation impaired) on TER responses to thrombin $\left(10 \mathrm{U} \mathrm{ml}^{-1}\right)$ in Zdhhc $21^{+/}+\mathrm{ECs}$. Solid line tracing represents the mean resistance, and shadow represents s.e.m. Embedded bar graph shows peak TER value changes. Bar graph represents mean \pm s.e.m. from three independent experiments. n.s. $=$ not significant. (f) The effect of overexpressing wild-type PLC $\beta 1$ on TER responses to thrombin $\left(10 \cup \mathrm{ml}^{-1}\right)$ in Zdhhc21dep/dep ECs. Solid line tracing represents the mean resistance, and shadow represents s.e.m. Embedded bar graph shows peak TER changes. Bar graph represents mean \pm s.e.m. from three independent experiments.

n.s. $=$ not significant. 
endothelial cells, regardless of inflammatory states or the presence of DHHC21 function. In contrast, the membrane localization of PKC, a downstream effector of PLC signalling known to translocate to cell membrane upon activation, was increased after stimulation and this effect was attenuated in DHHC21 deficient cells. The PKC activation response correlates with those of other PLC $\beta 1$ downstream effectors such as IP3 and calcium, supporting a common role of PLC $\beta 1$ palmitoylation at the upstream of the signalling pathway. Thus, we propose that in response to inflammatory mediators or GPCR ligands (histamine, thrombin), endothelial signalling proteins downstream of their receptors (PLC $\beta 1)$ undergo DHHC21-catalysed palmitoylation rendering enhanced signalling activities. Similar to kinases, DHHC21 may activate PLC $\beta 1$ by altering its enzymatic activity, molecular conformation, intracellular location, or ability to interact with other molecules. The possibility of PATs acting as kinase-like factors is supported by the similarity of palmitoylation-depalmitoylation and phosphorylationdephosphorylation with respect to their reversible kinetics and rapid nature of reactions. The molecular mechanisms by which PLC activation induces endothelial cell contraction and paracellular permeability have been extensively investigated in our lab and others ${ }^{18,50-52}$. The downstream effectors of PLC (PKC, IP3 and calcium) and their interactions with cell-cell adhesion molecules including ICAM-1 are discussed in more detail elsewhere ${ }^{53-56}$

In addition to the PLC cascade, other signalling or structural molecules may be involved in palmitoylation-mediated endothelial responses. In particular, several endothelial palmitoylproteins have been identified as direct substrates of DHHC2 $1^{39,57,58}$, including platelet endothelial cell adhesion molecule (PECAM-1), eNOS, caveolin-1, SOD1 and Fyn, many of which have been implicated in endothelial inflammation ${ }^{51}$. For example, PECAM-1 facilitates leucocyte transendothelial migration, Fyn mediates dissociation of endothelial cell-cell junctions, and eNOS-derived NO increases vascular permeability ${ }^{50,59,60}$. In a recent study, DHHC21 knockdown resulted in decreased eNOS palmitoylation and impaired NO release ${ }^{39}$. Another study showed that inactivation of fatty-acid synthase caused endothelial barrier dysfunction via decreased eNOS palmitoylation ${ }^{61}$. The discrepant findings from these two studies might result from different experimental conditions used to manipulate palmitoylation; in particular, fatty-acid synthase is not a PAT but a multifunctional enzyme associated with palmitate production. Overall, the limited availability of PAT knockout models, along with the well-recognized technical difficulties in quantification of DHHC-specific activities, contributes to the paucity of information regarding palmitoylation substrates and functions. Thus, further work elucidating the full spectrum of quiescent and inflammation-induced DHHC21 targets in vascular endothelium would advance the pathophysiology of SIRS, while facilitating cell-targeting drug development. In this regard, our novel findings build an important foundation for future studies in this rapidly expanding field.

In summary, the present study demonstrates that DHHC21PAT plays a critical role in mediating endothelial dysfunction during inflammation. The underlying mechanisms involve endothelial junction hyperpermeability and increased ICAM-1 expression mediated by palmitoylation of endothelial signalling molecules including PLC $\beta 1$. Targeting specific PATs, especially DHHC21, may serve as an effective therapeutic tool for treating vascular diseases or inflammatory injury.

\section{Methods}

Reagents and supplies. A complete list of reagents, supplies, company information and catalogue numbers can be found in Supplementary Tables 2-5.
Animals. All rats used in these studies were male Sprague-Dawley (SD) purchased from Harlan Laboratories weighing $300-350 \mathrm{~g}$. All mice $(20-30 \mathrm{~g})$ used in these studies were either wild-type $\left(Z d h h c 21^{+/+}\right)$or homozygous depilated mice that contain a spontaneous mutation in the Zdhhc21 gene, Zdhhc21 dep/dep mice. These mice were purchased from Jackson Laboratory ${ }^{37}$. To confirm murine genotype, tissue samples were sent for sequencing (Genewiz, Inc., NJ, USA). The primers for sequencing $Z d h h c 21^{\text {dep/dep }}$ were: AGCTGACTGAAGGGCACC (F); AAAACCTGTAACGCATTTCCA (R). Animals were maintained under a 12/12-hour light/dark cycle with food and water ad libitum. Animals were randomly allocated to experiment groups using random number table by investigators. The information regarding the animal strain, age and sex are provided in Supplementary Table 6. All surgical and experimental procedures involving animals were approved by the University of South Florida Institutional Animal Care and Use Committee.

Induction of Systemic Inflammatory Response Syndrome (SIRS). SIRS was induced in animals subjected to thermal trauma (sterile inflammation) or septic injury (infectious inflammation). Thermal injury was performed based on a modified Walker and Mason burn model ${ }^{62}$. Briefly, mice or rats were anesthetized with $1.75 \times 10^{3} \mathrm{mg} \mathrm{kg}^{-1}$ urethane. The sides and back of the anesthetized animals were shaved carefully. Hot water at $100{ }^{\circ} \mathrm{C}$ was applied for $9 \mathrm{~s}$ on the dorsal surface of the mouse to induce a full-thickness scald burn covering $25 \%$ total body surface area (TBSA) (40\% TBSA in rats). For resuscitation $37^{\circ} \mathrm{C}$ Lactated Ringer's (LR) fluid ( $4 \mathrm{ml} \mathrm{kg}^{-1} \times$ per cent TBSA, according to Parkland formula ${ }^{62}$ ) was injected subcutaneously on the dorsum of the animal immediately post burn. For sham groups, animals were subjected to the same treatment except the water temperature was $37^{\circ} \mathrm{C}$. To induce septic SIRS, ultra-pure E. coli lipopolysaccharide (LPS) was freshly dissolved in LR. Rats or mice were injected (IP) with LPS at the dose of $10 \mathrm{mg} \mathrm{kg}^{-1}$. Control rats or mice received LR alone. For thermal injury survival studies, SIRS was induced as mentioned above, except isoflurane was used for anaesthesia during induction. All animals were monitored $48 \mathrm{~h}$ post-induction. For LPS survival studies, mice were monitored $72 \mathrm{~h}$ post-induction.

Lung injury score survey. SIRS induction was performed as above. After $24 \mathrm{~h}$, mice were anesthetized, exsanguinated by transcardial perfusion with PBS, and perfusion fixed with $4 \%$ paraformaldehyde. The lungs were carefully excised, post-fixed in $10 \%$ neutral buffered formalin for $48 \mathrm{~h}$, and sent to HistoWiz Inc for processing, embedding, sectioning, staining, and imaging. The lung injury was evaluated and scored by two blinded investigators based on the following histological features: (1) alveolar wall thickness, (2) exudate accumulation and (3) interstitial leucocyte infiltration ${ }^{63}$. The extent of injury for each parameter was graded from 0 to 3 based on the severity. A composite score was calculated for each mouse on a scale of $0-6$.

Intravital microscopy analysis of protein transvascular flux. Plasma protein flux across mesenteric microvessels was measured. Mice or rats were anesthetized with an intramuscular injection of urethane at $1.75 \times 10^{3} \mathrm{mg} \mathrm{kg}^{-1}$. Cannulation of the left jugular vein was performed for IV infusion of drugs or solutions. Animals were restrained and body temperature was maintained at $37^{\circ} \mathrm{C}$ with a heating pad (Fine Science Tools, North Vancouver, BC). The abdomen of the animal was shaved, a midline laparotomy was performed, and a section of mesentery from the proximal ileum was exteriorized over an optical stage for microscopic observation. To prevent the exteriorized mesentery from drying it was constantly superfused with $37^{\circ} \mathrm{C} \mathrm{LR}$ solution. Continuous IV infusion of LR at $0.04 \mathrm{ml} \mathrm{min}^{-1} \mathrm{~kg}^{-1}$ body weight was given to replenish fluid loss during the experiment. The mesenteric microcirculation was examined using a Nikon Eclipse E600FN Microscope under a $\times 10$ working distance objective (Nikon Instruments Inc., NY, USA) equipped with a Cascade 512F digital camera (Photometrics, AZ, USA). To quantify transvascular flux of plasma proteins animals were given an IV bolus of fluorescein isothiocyanate conjugated bovine albumin (FITC-albumin) at $100 \mathrm{mg} \mathrm{kg}^{-1}$ (rats) or $15 \mathrm{mg} \mathrm{kg}^{-1}$ (mice), followed by continuous infusion at $0.15 \mathrm{mg} \mathrm{kg}^{-1} \mathrm{~min}^{-1}$ to maintain a constant plasma concentration. Postcapillary venules were selected for measurement of FITC-albumin flux. FITC-albumin leaking into extra-vascular space was accumulated over time. Fluorescent images were acquired every $5 \mathrm{~min}$ for $1 \mathrm{~h}$ and analysed using ImageJ (v1.48i; NIH, USA). Fluorescence intensity (I) was measured from windows positioned inside (Ii) and outside (Io) a selected venule. Time dependent FITC-albumin transvascular flux was calculated with the following equation: $\left[1-\frac{I i-I o}{I i}\right](1)$. Mesenteric transvascular flux in SIRS and sham-SIRS was started $3 \mathrm{~h}$ after the thermal injury. $2 \mathrm{mg} \mathrm{kg}^{-1} 2$-BP or vehicle was given IV $20 \mathrm{~min}$ before thermal injury. For histamine challenge in $Z d h h c 21^{+1+}$ versus $Z d h h c 21^{\text {dep/dep }}$ mice, baseline transvascular flux was obtained followed by exchange of $10 \mu \mathrm{M}$ histamine in LR as the superfused buffer.

Measurement of hydraulic conductivity. Microvascular permeability to water was determined using a modified Landis micro-occlusion technique that measures fluid filtration across unit areas of the microvascular wall under a set of controlled perfusion pressures. Briefly, rats were anesthetized with $1.75 \times 10^{3} \mathrm{mg} \mathrm{kg}^{-1}$ intramuscular injection of urethane. The rat mesentery was exteriorized and superfused with $\mathrm{LR}$ solution at $37^{\circ} \mathrm{C}$. The microcirculation was observed through a 
CKX41 Inverted Microscope (Olympus, PA, USA) under a $\times 20$ working distance objective, and images were recorded via a CoolSNAP $\mathrm{ES}^{2}$ video camera (Photometrics). A single postcapillary venule $(30-50 \mu \mathrm{m}$ in diameter) was cannulated with a micropipette containing $10 \mathrm{mg} \mathrm{ml}^{-1}$ BSA and red blood cells as markers. The micropipette was connected to a water manometer, allowing continuous flow of the perfusate under controlled intraluminal hydrostatic pressures. After equilibration, the downstream of the vessel was occluded with a glass rod. The initial transvascular flow per unit area of the vessel wall $\left(J_{\mathrm{v}} / \mathrm{A}\right)$ was measured. Hydraulic conductivity $\left(L_{\mathrm{p}}\right)$ was calculated as the ratio of $J_{\mathrm{v}} / \mathrm{A}$ to perfusion pressure: $L_{\mathrm{p}}=\left(J_{\mathrm{v}} / \mathrm{A}\right) / \mathrm{P}(2) .2-\mathrm{BP}$ was administrated $30 \mathrm{~min}$ before histamine stimulation and continuously perfused until the end of the observation. Measurements were made for a $30-\mathrm{min}$ period at 5 -min intervals.

Lung solute extravasation assays. Vascular permeability to solutes was assessed by measuring extravasation of the plasma albumin marker Evans blue (EB) and small molecule marker Sulfo-N-hydroxysuccinimide (NHS)-biotin. For EB extravasation, mice or rats received $160 \mathrm{mg} \mathrm{kg}^{-1} \mathrm{~EB}$ IV allowing circulation for $30 \mathrm{~min}$. Circulation was replaced with LR fluid by performing transcardiac perfusion. To determine EB concentration, the flushed lungs were removed and homogenized in $1 \mathrm{ml}$ PBS. Lung homogenates were incubated with $2 \mathrm{ml}$ formamide (Sigma, F9037) at $60^{\circ} \mathrm{C}$ for $18 \mathrm{~h}$ to extract $\mathrm{EB}$ and centrifuged at $5000 \mathrm{~g}$ for $30 \mathrm{~min}$. The concentration of $\mathrm{EB}$ in the supernatant was detected by a dual wavelength spectrophotometric method at 620 and $740 \mathrm{~nm}$ using the following formula: $\mathrm{E}_{620}($ corrected $)=\mathrm{E}_{620}-\left(1.426 \times \mathrm{E}_{740}+0.030\right)(3)$. A standard solution of $\mathrm{EB}$ in formamide was freshly made at the concentrations of $0,1,2,4,8,16,32$, $64 \mathrm{ng} \mathrm{ml}^{-1}$, and the results are presented as $\mathrm{ng}$ of EB per $\mathrm{mL}$ by comparing with the standard curve. To visualize EB extravasation, lungs were flushed, perfusionfixed, and post-fixed overnight in 4\% paraformaldehyde (PFA, ACROS, 41678). Following PBS washes, the entire left lobe was imaged for EB autofluorescence at $700 \mathrm{~nm}$ with an infrared imaging system (Odyssey CLx; Li-Cor) at a resolution of $21 \mu \mathrm{m}$. The same lobe was then embedded in $3 \%$ agarose and sliced into $1 \mathrm{~mm}$ transverse sections and imaged as above. The images were pseudo-colored with a heat-map colour scheme to highlight inter-sample signal intensity. For small solute permeability, sulfo-N-hydroxysuccinimide-biotin extravasation was performed ${ }^{64}$. Briefly, sham and SIRS rats were perfused with $30 \mathrm{ml} 0.3 \mathrm{mg} \mathrm{ml}^{-1}$ of the low molecular weight lysine-reactive biotinylation reagent, followed by perfusion fixation with $2 \%$ PFA, lung-excision and post-fixation in 2\% PFA. Lung slices of $1 \mathrm{~mm}$ and $100-150 \mu \mathrm{m}$ vibratome sections were incubated overnight in streptavidin conjugated with either IRdye-800 or Texas-Red (Vector, SA-5006) diluted in PBSTC (PBS $+0.5 \%$ Triton-X100 $+0.1 \mathrm{mM} \mathrm{CaCl}_{2}$ ) with $10 \%$ normal goat serum, and washed for $6 \mathrm{~h}$ in PBSTC. Slices were imaged as above in the Odyssey CLx at $800 \mathrm{~nm}$. Vibratome sections were mounted in vectashield with DAPI and confocal micrographs were obtained with Olympus FV1000 MPE laser scanning microscope.

\section{Intravital microscopic measurement of leucocyte dynamics. Leucocyte-} endothelial interactions were analysed in mesenteric and ear microcirculation. Rat LPS-SIRS was induced as above with or without 2-BP $\left(2 \mathrm{mg} \mathrm{kg}^{-1}\right.$; IV). after induction of $4 \mathrm{~h}$, rats were anesthetized with $1.75 \times 10^{3} \mathrm{mg} \mathrm{kg}^{-1}$ urethane. Rats were prepared for microscopic observation as mentioned above. Briefly, a loop of proximal ileum was exteriorized over an optical stage after midline laparotomy. Constant dripping of LR solution was applied to prevent the exteriorized mesentery from drying. Body temperature was maintained as described above. Leucocytes were fluorescently labelled with acridine orange $\left(0.25-0.5 \mathrm{ml} ; 1.65 \times 10^{-4} \mathrm{M}\right)$ and visualized in post-capillary venules using a Zeiss Axiovert 200 inverted microscope under a $\times 10$ Zeiss objective equipped with a Photometrics Cool Snap HQ2 camera (Photometrics, AZ, USA). The interaction of leucocytes with venular wall was recorded for $60 \mathrm{~s}$ in at least 3 venules per rat. Four parameters were measured to evaluate leucocyte interaction with mesenteric venular wall ${ }^{65}$ : slow-rolling flux, slow-rolling flux fraction, leucocyte rolling velocity and leucocyte adhesion. Rolling leucocytes were defined as leucocytes moving at a significantly reduced velocity compared with centerline blood flow velocity. Slow-rolling flux was quantified as the number of leucocytes rolling at the velocity of $<5 \mu \mathrm{m} \mathrm{s}^{-1}$ in the observed venule within $60 \mathrm{~s}$; slow-rolling flux fraction was as the percentage of the number of slow-rolling leucocytes to the total number of rolling leucocytes; leucocyte rolling velocity was determined as the average velocity of all rolling leucocytes in the observed venule. Leucocyte adhesion was measured by counting the number of adherent leucocytes (no visible movement for more than $20 \mathrm{~s}$ ) per $10^{5} \mu \mathrm{m}^{2}$. Video analyses and measurements were performed by an independent investigator blinded to experimental design. In separate groups of mice, leucocyte-endothelial interactions were recorded $4 \mathrm{~h}$ post-SIRS induction as above, except microscopic observations were made in venules of mouse ears secured to an optical stage.

Primary endothelial cell culture. Individual reagents, company information and catalogue numbers can be found in Supplementary Table 2. Cells were seeded in $0.1 \%$ gelatin coated culture flasks (Corning, NY, USA). Human umbilical vein endothelial cells (HUVECs, Lonza, MD, USA) were grown in Endothelial Cell Basal Medium supplemented with EGM-2 MV Bulletkits (Lonza, MD, USA). Primary mouse lung microvascular endothelial cells (MLMVECs, Cell Biologics,
Inc.) were cultured in Mouse Endothelial Cell Medium with Supplement Kit (Cell Biologics, Inc., IL, USA). All cells were incubated in a $5 \% \mathrm{CO}_{2}$ humidified incubator at $37^{\circ} \mathrm{C}$ to reach confluence $2-3$ days before experiments. Primary MLMVEC were commercially isolated (Cell Biologics, Inc.) from 5 to 8 day old Zdhhc $21^{+/+}$and $Z d h h c 21^{\text {dep/dep }}$ mice.

Leucocyte isolation. Whole blood from mice was obtained by cardiac puncture, and layered over a Histopaque 1077/1119 gradient. After centrifugation at $700 \mathrm{~g}$ for $30 \mathrm{~min}, \mathrm{RBC}$ lysis was performed, and white blood cells were rinsed and collected for use. Whole blood from humans was obtained commercially (AllCells, LLC). Leucocytes were isolated by mixing the blood with $6 \%$ dextran in normal saline and incubated for $1 \mathrm{~h}$ at room temperature. The supernatant was collected and centrifuged at $200 \mathrm{~g}$ for $12 \mathrm{~min}$. Leucocytes were washed, RBC lysis was performed, and leucocytes were rinsed and collected for use.

Endothelial barrier function assays In vitro. The barrier function of cultured endothelial cell monolayers was determined by measuring TER, an indicator of cell-cell adhesive barrier resistance, using an electric cell-substrate impedance sensing system (Applied Biophysics, Troy, NY) ${ }^{66}$. Electric cell-substrate impedance sensing tracings are expressed as TER normalized to baseline in untreated conditions. TER changes were recorded and submitted for statistical analyses of peak changes. In separate experiments, transendothelial flux of albumin was measured using a Transwell assay ${ }^{66}$. Briefly, $2 \times 10^{5}$ MLMVECs isolated from either $Z d h h c 21^{+1+}$ and $Z d h h c 21^{\text {dep }}$ dep mice were seeded in the upper 'luminal' chamber of $0.4 \mu \mathrm{m}$ Transwell inserts (Corning, MA, USA) that were coated with $0.1 \%$ gelatin and maintained in 24 -well culture dishes. Media was maintained at a ratio of $100 \mu \mathrm{l}$ in the luminal chamber and $670 \mu \mathrm{l}$ in the lower 'abluminal' chamber to insure negligible hydrostatic pressure. After culture for 2 days post-confluence, $20 \mu \mathrm{l}$ of media from luminal chamber was replaced with $10 \mu \mathrm{l}$ of media containing FITC-albumin $\left(5 \mathrm{mg} \mathrm{ml}^{-1}\right)$, followed by $10 \mu \mathrm{l}$ of media containing thrombin $\left(100 \mathrm{U} \mathrm{ml}^{-1}\right)$ or vehicle control $(0.1 \% \mathrm{BSA}$ in PBS). After $30 \mathrm{~min}$, samples were collected from both the luminal and abluminal chambers for fluorometry analysis. The concentration of FITC-albumin was determined using a standard curve, and the permeability coefficient of albumin $\left(P_{\mathrm{a}}\right)$ was calculated as follows: $P_{\mathrm{a}}=\left[C_{\mathrm{A}} / t\right] \times[1 / A] \times\left[V / C_{\mathrm{L}}\right](4)$, where $\left[C_{\mathrm{A}}\right]$ is the abluminal FITC-albumin concentration, $t$ is time (in seconds), $A$ is the area of the membrane (in $\mathrm{cm}^{2}$ ), $V$ is the volume of media in the abluminal chamber, and $\left[C_{\mathrm{L}}\right]$ is the luminal FITC-albumin concentration.

Leucocyte-endothelial cell adhesion assay. ECs were cultured to confluence on gelatin-coated coverslips. ECs were pre-stimulated for $4 \mathrm{~h}$ with vehicle control or $100 \mathrm{ng} \mathrm{ml}^{-1} \mathrm{IL}-1 \beta$. After stimulation, ECs were rinsed three times with warm HBSS. Prior to endothelial-leucocyte incubations, ECs were labelled with CellMask Deep Red Stain, and leucocytes were labelled with CellTracker Green as per manufacturer's instructions. Leucocytes were incubated with ECs for $1 \mathrm{~h}$. Before fixation (4\% PFA for $10 \mathrm{~min}$ ), non-adherent cells were washed three times with HBSS. Coverslips were mounted with Vectashield mounting medium containing DAPI. Images were acquired using Olympus FV1000 MPE laser-scanning microscope. The number of adherent leucocytes was counted and the results were presented as the number of adherent leucocytes per $10^{5} \mu \mathrm{m}^{2}$.

Immunocytochemistry. Immunocytochemistry (ICC) on confluent EC monolayers was performed per standard protocols. Briefly, after treatment with or without $1 \mathrm{~h}$ pretreatment of 2-BP, coverslips were fixed with $4 \%$ paraformaldehyde $\times 10 \mathrm{~min}$, permeabilized with $0.05 \%$ Triton X-100 in PBS $\times 10$ min, blocked with $5 \%$ BSA in PBST $\times 1 \mathrm{~h}$ and labelled with goat anti-VE-cadherin overnight at $4{ }^{\circ} \mathrm{C}$. Secondary incubation for $1 \mathrm{~h}$ was done with donkey anti-goat AlexaFluor568. Cell-surface ICC for ICAM-1 was performed as mentioned, except that detergents were omitted from all solutions and secondary antibody was donkey anti-rabbit Alexa Fluor 488. ProLong Diamond mounting medium with DAPI was used for mounting coverslips. Fluorescent images were captured with Olympus FV1000 Olympus MPE laser scanning microscope. Images were analysed via Imaris software (Bitplane). Briefly, the intensity threshold of VE-cadherin channel was set for each ICC image to label all the VE-cadherin positive regions (region of interest, ROI). The number of ROI was then counted without bias using Imaris. Continuous VE-cadherin staining corresponds with a lower number of ROI, whereas discontinuous staining corresponds to a higher number of ROI. The results of VE-cadherin discontinuity were presented as the number of ROI counted via Imaris.

On-cell western assay for ICAM-1 cell surface expression. On-Cell Western Assays were performed per the manufacturer's (Li-Cor) instructions and standardized protocols. Briefly, ECs were grown to confluence in gelatin-coated 96-well plates. After treatment, ECs were fixed and immunolabeled as per the ICC protocol for ICAM-1 surface staining. Total cell staining (CellTag) for normalization was performed during secondary antibody incubations. Images were scanned and analysed with Li-Cor Odyssey Clx. 
Real-time PCR. Total RNA from MLMVECs was extracted using RNAzol RT per manufacturer's instructions. RNA purity and concentration was quantified with an Agilent 2100 Bioanalyzer (Agilent Technologies, TX, USA). Total RNA of $1 \mu \mathrm{g}$ was used per $20 \mu \mathrm{L}$ of iScript cDNA Synthesis Kit. Prime PCR Reverse Transcriptase control was used during cDNA synthesis per the manufacturer's instructions. Wet-lab validated gene-specific PCR primers from Bio-Rad were used to analyse mRNA expression with PCR. Qualitative PCR amplifications were performed in a CFX Connect thermocycler with the following programme: 1 step of $2 \mathrm{~min}$ at $95^{\circ} \mathrm{C}, 35$ cycles of $15 \mathrm{~s}$ at $95^{\circ} \mathrm{C}, 30 \mathrm{~s}$ at $60^{\circ} \mathrm{C}$ and $5 \mathrm{~s}$ at $72^{\circ} \mathrm{C}$, and the final step of 7 min at $72^{\circ} \mathrm{C}$. PCR amplified products were electrophoresed in $4-20 \%$ Criterion precast polyacrylamide TBE gels $\sim 90 \mathrm{~min}$ at $150 \mathrm{~V}$ and stained with Syto 60 for visualization on Odyssey CLx.

Acyl-Biotin exchange. Acyl-Biotin Exchange (ABE) was performed per recently developed protocols with modifications ${ }^{57}$. HUVECs were treated with inflammatory stimuli and then lysed with lysis buffer $(50 \mathrm{mM}$ Tris, $5 \mathrm{mM}$ EDTA, $150 \mathrm{mM} \mathrm{NaCl}, 1 \% \mathrm{NP}-40,10 \%$ glycerol, $5 \mathrm{mM} \mathrm{MgCl}_{2}$, a tablet of complete ULTRA protease inhibitor, $\mathrm{pH}$ 7.4) on ice. Lysates were centrifuged at $13,000 \mathrm{~g}$ for $10 \mathrm{~min}$ at $4{ }^{\circ} \mathrm{C}$. Supernatants were collected and protein concentrations were determined using BCA assay. Proteins were precipitated using several volumes of ice-cold acetone for $30 \mathrm{~min}$ at $-20^{\circ} \mathrm{C}$, collected by centrifugation and resuspended in $37^{\circ} \mathrm{C} 4 \mathrm{SB}$ buffer ( $4 \%$ SDS, $5 \mathrm{mM}$ EDTA, $50 \mathrm{mM}$ Tris, $\mathrm{pH}$ 7.4). The solution was diluted to $1 \%$ SDS using lysis buffer. Methyl methanethiosulfonate (MMTS) was added to a final concentration of $20 \mathrm{mM}$ and the solution was incubated for $30 \mathrm{~min}$ at $50{ }^{\circ} \mathrm{C}$. Proteins were washed by three sequential rounds of precipitation in ice cold acetone followed by resuspension in $37^{\circ} \mathrm{C} 4 \mathrm{SB}$. Proteins were diluted to $1 \%$ SDS and split. Both samples were treated with $1 \mathrm{mM}$ biotin HPDP for $60 \mathrm{~min}$ at room temperature (RT). One sample was then treated with $1 \mathrm{M}$ hydroxylamine (HA, $\mathrm{pH}$ 7.4). The other half was treated with Tris buffer ( $\mathrm{pH}$ 7.4) as control. Proteins were washed three times with acetone and resuspended in 4SB buffer. The solution was diluted to $1 \mathrm{ml}$ with dilution buffer $(50 \mathrm{mM}$ Tris, $150 \mathrm{mM} \mathrm{NaCl}, 5 \mathrm{mM}$ EDTA, $0.2 \%$ Triton-X 100, pH 7.4). To each tube $100 \mu \mathrm{l}$ prewashed streptavidinconjugated agarose beads were added and rocked overnight at $4{ }^{\circ} \mathrm{C}$. The beads were washed three times with dilution buffer and the captured proteins were eluted using $100 \mu \mathrm{l}$ dilution buffer with $1 \% \beta$-mercaptoethanol. BCA assay was performed again, and $4 \times$ sample buffer with $2.5 \% \beta$-mercaptoethanol was added to proteins. Samples were loaded into gels for mass spectrometry mail-out and/or subsequent western blotting per standard protocols.

Click chemistry. Confluent HUVEC monolayers were incubated with $100 \mu \mathrm{M}$ Alk-C16 overnight to metabolically label palmitoylated proteins. Alk-C16 was prepared as follows: (1) dissolved in DMSO to the stock concentration of $50 \mathrm{mM}$, (2) diluted to a final concentration of $100 \mu \mathrm{M}$ using EC culture medium with charcoal stripped FBS, (3) sonicated for $15 \mathrm{~min}$ at room temperature before use. Confocal microscopic imaging was then performed to analyse palmitoylated proteins ${ }^{67}$. After metabolic labelling with Alk-C16, ECs grown on coverslips were then treated with $10 \mathrm{U} \mathrm{ml}^{-1}$ thrombin, $10 \mu \mathrm{M}$ histamine or $20 \%$ SIRS plasma with or without $3 \mathrm{~h}$ pretreatment of $10 \mu \mathrm{M} 2$-BP. After washing with HBSS once, cells were fixed with pre-chilled methanol for $10 \mathrm{~min}$ in $-20^{\circ} \mathrm{C}$. Cells were then permeabilized with $0.1 \%$ Triton X-100 in PBS for $5 \mathrm{~min}$ and washed with PBS six times. Click reaction solution was freshly made: $0.1 \mathrm{mM}$ Oregon Green 488 azide ( $5 \mathrm{mM}$ stock solution in DMSO), $1 \mathrm{mM}$ Tris (2-carboxethyl) phosphine hydrochloride (TCEP, $50 \mathrm{mM}$ freshly prepared stock solution in $\mathrm{ddH}_{2} 0$ ), $0.1 \mathrm{mM}$ tris[(1-benzyl-1H-1,2,3-triazol-4-yl)methyl]amine (TBTA, $10 \mathrm{mM}$ stock solution in DMSO/tert-butanol $(20 \% / 80 \% \mathrm{~V} / \mathrm{V}))$ and $1 \mathrm{mM} \mathrm{CuSO}_{4}(50 \mathrm{mM}$ stock solution in $\mathrm{ddH}_{2} \mathrm{O}$ ) in $\mathrm{ddH}_{2} \mathrm{O}$. Cells were treated with click reaction solution for $1 \mathrm{~h}$ in dark at room temperature, and then wash six times with PBS. ProLong Diamond mounting medium with DAPI was used for mounting coverslips. Images were acquired using Olympus FV1000 MPE laser-scanning microscope. The fluorescence intensity of palmitoylated proteins was analysed by Image J (v1.48i, NIH, USA).

PLC $\beta 1$ palmitoylation assay. After metabolic labelling palmitoylated proteins, ECs were treated with $10 \mu \mathrm{M}$ histamine. Cells were then lysed with $1 \times$ RIPA buffer with a tablet of complete ULTRA protease inhibitor based on standardized protocol. To remove excess Alk-C16, samples were then subjected to chloroformmethanol protein precipitate where 4 volumes of methanol, 1 volume of chloroform and 3 volumes of $\mathrm{ddH}_{2} \mathrm{O}$ were sequentially added. Samples were then separated into two layers via centrifugation at $14,000 \mathrm{~g}$ for $2 \mathrm{~min}$ with precipitated proteins located between the two layers. After removing the top layer, 4 volumes of methanol were added. Proteins were pelleted by centrifugation at $14,000 \mathrm{~g}$ for $5 \mathrm{~min}$. After removing supernatant, samples were air-dried for 5 min. Precipitated protein pellets were dissolved in $1 \%$ SDS and the protein concentrations were determined using BCA assay. Azide agarose resin was prepared according to manufacturer's instructions. Click chemistry solution $(2 \mathrm{mM}$ TCEP, $0.4 \mathrm{mM}$ TBTA and $2 \mathrm{mM}$ $\mathrm{CuSO}_{4}$ ) was freshly made before use. For each sample, $200 \mu \mathrm{L}$ prepared agarose resin slurry, $800 \mu \mathrm{L}$ protein sample and $1 \mathrm{ml}$ Click chemistry solution were mixed thoroughly and incubated with end-over-end rotation for $20 \mathrm{~h}$ at $4{ }^{\circ} \mathrm{C}$. Samples were then washed six times with washing buffer (100 mM Tris, $1 \%$ SDS, $250 \mathrm{mM}$
$\mathrm{NaCl}, 5 \mathrm{mM}$ EDTA, $\mathrm{pH}$ 8.0). After eluted by hydroxylamine (1 M, pH 7.0), proteins were precipitated and re-dissolved in $1 \times$ protein loading buffer. Alternatively, palmitoylated proteins on agarose resin were eluted by $1 \times$ protein loading buffer containing a high concentration of $\beta$-mercaptoethanol $(1.43 \mathrm{M})$. The level of palmitoylated PLC $\beta 1$ in eluted samples was then determined with Western blotting.

Resin-assisted capture. The level of palmitoylated protein was detected by resin-assisted capture ${ }^{68}$. Confluent MLMVECs were treated with $20 \mathrm{U} \mathrm{ml}^{-1}$ thrombin for $5 \mathrm{~min}$ and then lysed in lysis buffer $(100 \mathrm{mM}$ HEPES, $25 \mathrm{mM} \mathrm{NaCl}$, $1 \mathrm{mM}$ EDTA, $10 \mu \mathrm{M}$ palmostatin B, protease inhibitors, $\mathrm{pH}$ 7.4). Cell lysate was then sonicated and incubated with blocking buffer (100 mM HEPES, 1 mM EDTA $\left.2.5 \% \mathrm{SDS}, 6 \mu \mathrm{l} \mathrm{ml}^{-1} \mathrm{MMTs}, \mathrm{pH} 7.4\right)$ at $50^{\circ} \mathrm{C}$ for $30 \mathrm{~min}$ with frequent vortexing. 4 volumes of cold acetone were added and incubated at $-20^{\circ} \mathrm{C}$ overnight to allow protein precipitation. Following centrifugation of the solution at 2,500g for $30 \mathrm{~min}$ the protein pellet was washed with $70 \%$ cold acetone three times, and resuspended into binding buffer (100 mM HEPES, $1 \mathrm{mM}$ EDTA, $1.0 \%$ SDS, pH 7.4). Protein quantification was performed and total protein amount for each group was normalized. The protein sample was split into two equal parts. Hydroxylamine $(\mathrm{pH}=7.4$, final concentration of $0.2 \mathrm{M})$ and prewashed water-swollen thiopropyl sepharose $6 \mathrm{~B}$ were added into one part. To the other part, an equal amount of $\mathrm{NaCl}$ and beads were added. The binding reaction of the beads and palmitoylated protein were carried out at room temperature for $4 \mathrm{~h}$ with constant rotation. Beads were washed five times with binding buffer, then eluted with $1 \times$ sample buffer supplemented with $50 \mathrm{mM}$ DTT at room temperature for $30 \mathrm{~min}$. The solution mixture was heated to $95^{\circ} \mathrm{C}$ for $5 \mathrm{~min}$ and centrifuged at $14,000 \mathrm{~g}$ for $5 \mathrm{~min}$. Supernatant was collected for SDS-PAGE.

Membranous and cytosolic fractionation assay. Isolated MLMVECs were treated with thrombin $\left(10 \mathrm{U} \mathrm{ml}^{-1}\right)$ for $3 \mathrm{~min}$. After washing three times with cold HBSS, ECs were lysed. Plasma membrane fraction of EC lysate was separated from cytosol fraction via Plasma Membrane Isolation Kit per manufacturer's instructions. Purified cellular fractions were then subject to Western blot.

IP3 ELISA. HUVECs were treated with histamine $(10 \mu \mathrm{M})$, and or 2-BP $(100 \mu \mathrm{M})$ and immediately harvested, frozen and used for determining IP3 concentrations with an IP3 ELISA Kit per the manufacturer's instructions.

Time-Lapse $\mathbf{C a}^{2}+$ Imaging. Primary MLMVECs isolated from wild-type and $Z d h h c 21^{\text {dep/dep }}$ mice were grown to confluence on glass bottom culture dishes. Prior to imaging and thrombin stimulation, cells were prepared with the reagents from the Fluo-4 Calcium Imaging Kit per the manufacturer's instructions. Time-lapse images were acquired with $3 \mathrm{i}$ spinning disk confocal system (Intelligent Imaging Innovations) on an Olympus IX81 inverted microscope equipped with a stage-top microenvironmental chamber (Pathology Device) for constant $37^{\circ} \mathrm{C}$ and $5 \% \mathrm{CO}_{2}$. Time-lapse images were obtained with Olympus 20X UPLSAPO (NA 0.75 ) objective by acquiring images every second with Slidebook 6.0 software (Intelligent Imaging Innovations). To minimize spontaneous $\mathrm{Ca}^{2+}$ release due to exposure to the laser, cells were illuminated with $50 \%$ laser power and the fluorescence was captured with Evolve EMCCD (Photometrics) with a setting of 17-ms exposure and intensification mode. The relative fluorescence intensity fluctuation during the time-lapse was analysed by Slidebook 6.0.

siRNA Transfection and gene transfer. All $Z d h h c$ and PLC $\beta 1$ siRNA were purchased from Santa Cruz Biotech. pCMV6 empty vector, and ZDHHC21 plasmids were purchased from Origene; and pLX304 empty vector and PLC $\beta 1$ plasmids were purchased from Genecopoeia. MLMVECs grown to $90 \%$ confluence were trypsinized, pelleted, and resuspended in $100 \mu \mathrm{l}$ of P5 Primary Cell $4 \mathrm{D}$-Nucleofector ${ }^{\mathrm{TM}} \mathrm{X}$ with $1 \mu \mathrm{M}$ siRNA or $2 \mu \mathrm{g}$ plasmid. Cells were rapidly electroporated using the $4 \mathrm{D}$-Nucleofector ${ }^{\mathrm{TM}}$ System (Lonza, MD, USA) and plated in Endothelial cell complete medium (Cell Biologics) for experiments. Mutation at potential palmitoylation site of PLC $\beta 1$ was created by mutagenesis using as template the pLX304 with PLC $\beta 1$ transcript variant 1 cDNA clone purchased from Genecopoeia; and the Q5 Site-Directed Mutagenesis Kit with supplied 5-alpha competent cells purchased from New England BioLabs. PLC $\beta 1$ C17S mutagenesis primers (Fw: $5^{\prime}$ AAGCCCGTGTCCGTGTCCGAC 3'; Rev: 5' GAGTTGCAAGGC GTGCAC $3^{\prime}$ ) were designed using the NEBaseChanger tool also provided by New England BioLabs. Successful mutation of $\mathrm{C} 17 \mathrm{~S}$ was confirmed by sequencing using (Fw: 5' ACATCAATGGGCGTGGATAG 3'; Rev 5' GGAAAGCCACGAGATT CAAATG $3^{\prime}$ ) designed with the PrimerQuest tool provided by Integrated DNA Technologies and Sanger sequencing of PCR product provided by Genewiz.

Statistical analysis. All statistics were performed using GraphPad Prism (version 6.0f). See Supplementary Table 7 for a list of statistical tests used for all data analyses. Statistical tests were justified as appropriate. All data meet the normal distribution assumption. The variance is similar between groups that are being statistically compared. The sample size was derived from a priori power analysis 
based on the expected effect sizes observed in previous studies in our lab for each endpoint measurement and literature searches for commonly observed means and standard deviations between groups.

Data availability. The authors declare that the data supporting the findings of this study are available within the article and its supplementary information files.

\section{References}

1. Cohen, J. et al. Sepsis: a roadmap for future research. Lancet Infect. Dis. 15, 581-614 (2015).

2. Jeschke, M. G. et al. Morbidity and survival probability in burn patients in modern burn care. Crit. Care Med. 43, 808-815 (2015).

3. Lord, J. M. et al. The systemic immune response to trauma: an overview of pathophysiology and treatment. Lancet 384, 1455-1465 (2014).

4. Plackett, T. P. et al. The early acute phase response after burn injury in mice. J. Burn Care Res.: Off. Publ. Am. Burn Assoc. 28, 167-172 (2007).

5. Seymour, C. W. \& Rosengart, M. R. Septic shock: advances in diagnosis and treatment. J. Am. Med. Assoc. 314, 708-717 (2015).

6. Opal, S. M. et al. Effect of eritoran, an antagonist of MD2-TLR4, on mortality in patients with severe sepsis: the ACCESS randomized trial. J. Am. Med. Assoc. 309, 1154-1162 (2013).

7. Hoffmann, J. N. et al. Benefit/risk profile of high-dose antithrombin in patients with severe sepsis treated with and without concomitant heparin. Thromb. Haemost. 95, 850-856 (2006).

8. Griffin, J. H., Zlokovic, B. V. \& Mosnier, L. O. Activated protein C: biased for translation. Blood 125, 2898-2907 (2015).

9. Natarajan, V. et al. Sphingosine-1-phosphate, FTY720, and sphingosine-1phosphate receptors in the pathobiology of acute lung injury. Am. J. Respir. Cell Mol. Biol. 49, 6-17 (2013).

10. Andersson, U. \& Tracey, K. J. HMGB1 is a therapeutic target for sterile inflammation and infection. Ann. Rev. Immunol. 29, 139-162 (2011).

11. Muller, W. A. Leukocyte-endothelial-cell interactions in leukocyte transmigration and the inflammatory response. Trends Immunol. 24, 327-334 (2003).

12. Norman, M. U. \& Kubes, P. Therapeutic intervention in inflammatory diseases: a time and place for anti-adhesion therapy. Microcirculation 12, 91-98 (2005).

13. Yuan, S. Y. et al. Myosin light chain phosphorylation in neutrophil-stimulated coronary microvascular leakage. Circ. Res. 90, 1214-1221 (2002).

14. Rizzo, A. N., Aman, J., van Nieuw Amerongen, G. P. \& Dudek, S. M. Targeting Abl kinases to regulate vascular leak during sepsis and acute respiratory distress syndrome. Arterioscler. Thromb. Vasc. Biol. 35, 1071-1079 (2015).

15. Lemmon, M. A. \& Schlessinger, J. Cell signaling by receptor tyrosine kinases. Cell 141, 1117-1134 (2010).

16. Kumar, P. et al. Molecular mechanisms of endothelial hyperpermeability: implications in inflammation. Expert Rev. Mol. Med. 11, e19 (2009).

17. Pober, J. S. \& Sessa, W. C. Evolving functions of endothelial cells in inflammation. Nat. Rev. Immunol. 7, 803-815 (2007).

18. Yuan, S. Y. Protein kinase signaling in the modulation of microvascular permeability. Vasc. Pharmacol. 39, 213-223 (2002).

19. Marin, N. et al. S-Nitrosation of beta-catenin and p120 catenin: a novel regulatory mechanism in endothelial hyperpermeability. Circ. Res. 111, 553-563 (2012).

20. Linder, M. E. \& Deschenes, R. J. Model organisms lead the way to protein palmitoyltransferases. J. Cell Sci. 117, 521-526 (2004).

21. Roth, A. F., Feng, Y., Chen, L. \& Davis, N. G. The yeast DHHC cysteine-rich domain protein Akrlp is a palmitoyl transferase. J. Cell Biol. 159, 23-28 (2002).

22. Lobo, S., Greentree, W. K., Linder, M. E. \& Deschenes, R. J. Identification of a Ras palmitoyltransferase in Saccharomyces cerevisiae. J. Biol. Chem. 277, 41268-41273 (2002)

23. Blaskovic, S., Adibekian, A., Blanc, M. \& van der Goot, G. F. Mechanistic effects of protein palmitoylation and the cellular consequences thereof. Chem. Phys. Lipids 180, 44-52 (2014).

24. Akimzhanov, A. M. \& Boehning, D. Rapid and transient palmitoylation of the tyrosine kinase Lck mediates Fas signaling. Proc. Natl Acad. Sci. USA 112, 11876-11880 (2015).

25. Brigidi, G. S., Santyr, B., Shimell, J., Jovellar, B. \& Bamji, S. X. Activity-regulated trafficking of the palmitoyl-acyl transferase DHHC5. Nat. Commun. 6, 8200 (2015).

26. Li, Y., Martin, B. R., Cravatt, B. F. \& Hofmann, S. L. DHHC5 protein palmitoylates flotillin-2 and is rapidly degraded on induction of neuronal differentiation in cultured cells. J. Biol. Chem. 287, 523-530 (2012).

27. Noritake, J. et al. Mobile DHHC palmitoylating enzyme mediates activity-sensitive synaptic targeting of PSD-95. J. Cell Biol. 186, 147-160 (2009).

28. Mo, M. L. et al. Inhibition of the Wnt palmitoyltransferase porcupine suppresses cell growth and downregulates the Wnt/beta-catenin pathway in gastric cancer. Oncol. Lett. 5, 1719-1723 (2013).
29. Wei, X., Song, H. \& Semenkovich, C. F. Insulin-regulated protein palmitoylation impacts endothelial cell function. Arterioscler. Thromb. Vasc. Biol. 34, 346-354 (2014).

30. Young, F. B., Butland, S. L., Sanders, S. S., Sutton, L. M. \& Hayden, M. R. Putting proteins in their place: palmitoylation in Huntington disease and other neuropsychiatric diseases. Prog. Neurobiol. 97, 220-238 (2012).

31. Zhao, Y., McCabe, J. B., Vance, J. \& Berthiaume, L. G. Palmitoylation of apolipoprotein B is required for proper intracellular sorting and transport of cholesteroyl esters and triglycerides. Mol. Biol. Cell 11, 721-734 (2000).

32. Kumano-Kuramochi, M. et al. Lectin-like oxidized LDL receptor-1 is palmitoylated and internalizes ligands via caveolae/raft-dependent endocytosis. Biochem. Biophys. Res. Commun. 434, 594-599 (2013).

33. Marin, E. P. et al. The protein acyl transferase ZDHHC21 modulates alpha1 adrenergic receptor function and regulates hemodynamics. Arterioscler. Thromb. Vasc. Biol. 36, 370-379 (2016).

34. Davda, D. et al. Profiling targets of the irreversible palmitoylation inhibitor 2-bromopalmitate. ACS Chem. Biol. 8, 1912-1917 (2013).

35. Giannotta, M., Trani, M. \& Dejana, E. VE-cadherin and endothelial adherens junctions: active guardians of vascular integrity. Dev. Cell 26, 441-454 (2013).

36. Ohno, Y., Kihara, A., Sano, T. \& Igarashi, Y. Intracellular localization and tissue-specific distribution of human and yeast DHHC cysteine-rich domain-containing proteins. Biochim. Biophys. Acta 1761, 474-483 2006.

37. Mill, P. et al. Palmitoylation regulates epidermal homeostasis and hair follicle differentiation. PLoS Genet. 5, e1000748 (2009).

38. Ren, J. et al. CSS-Palm 2.0: an updated software for palmitoylation sites prediction. Protein Eng. Des. Sel.: PEDS 21, 639-644 (2008).

39. Fernandez-Hernando, C. et al. Identification of Golgi-localized acyl transferases that palmitoylate and regulate endothelial nitric oxide synthase. J. Cell Biol. 174, 369-377 (2006).

40. Lemonidis, K. et al. The zDHHC family of S-acyltransferases. Biochem. Soc. Trans. 43, 217-221 (2015).

41. Berchtold, L. A. et al. Huntingtin-interacting protein 14 is a type 1 diabetes candidate protein regulating insulin secretion and beta-cell apoptosis. Proc. Natl Acad. Sci. USA 108, E681-E688 (2011).

42. Greaves, J. \& Chamberlain, L. H. New links between S-acylation and cancer. J. Pathol. 233, 4-6 (2014).

43. Fukata, Y., Iwanaga, T. \& Fukata, M. Systematic screening for palmitoyl transferase activity of the DHHC protein family in mammalian cells. Methods 40, 177-182 (2006)

44. Draper, J. M. \& Smith, C. D. Palmitoyl acyltransferase assays and inhibitors. Mol. Membr. Biol. 26, 5-13 (2009).

45. Ducker, C. E. et al. Discovery and characterization of inhibitors of human palmitoyl acyltransferases. Mol. Cancer Ther. 5, 1647-1659 (2006).

46. Jennings, B. C. et al. 2-Bromopalmitate and 2-(2-hydroxy-5-nitrobenzylidene)-benzo[b]thiophen-3-one inhibit DHHC-mediated palmitoylation in vitro. J. Lipid Res. 50, 233-242 (2009).

47. Veluthakal, R., Kumar, B., Mohammad, G., Kowluru, A. \& Kowluru, R. A. Tiam1-Rac1 axis promotes activation of p38 MAP kinase in the development of diabetic retinopathy: evidence for a requisite role for protein palmitoylation. Cell. Physiol. Biochem.: Int. J. Exp. Cell. Physiol. Biochem. Pharmacol. 36, 208-220 (2015).

48. Oakes, N. D. \& Furler, S. M. Evaluation of free fatty acid metabolism in vivo. Ann. N. Y. Acad. Sci. 967, 158-175 (2002).

49. Pedro, M. P. et al. 2-Bromopalmitate reduces protein deacylation by inhibition of acyl-protein thioesterase enzymatic activities. PloS ONE 8, e75232 (2013).

50. Yuan, Y., Granger, H. J., Zawieja, D. C., DeFily, D. V. \& Chilian, W. M. Histamine increases venular permeability via a phospholipase C-NO synthase-guanylate cyclase cascade. Am. J. Physiol. 264, H1734-H1739 (1993)

51. Yuan, S. Y. \& Rigor, R. R. Regulation of Endothelial Barrier Function. San Rafael (CA):Morgan \& Claypool Life Sciences (2010).

52. Mehta, D. \& Malik, A. B. Signaling mechanisms regulating endothelial permeability. Physiol. Rev. 86, 279-367 (2006).

53. Michel, C. C. \& Curry, F. E. Microvascular permeability. Physiol. Rev. 79, 703-761 (1999).

54. Krunkosky, T. M. et al. Effects of TNF-alpha on expression of ICAM-1 in human airway epithelial cells in vitro. Signaling pathways controlling surface and gene expression. Am. J. Respiratory Cell Mol. Biol. 22, 685-692 (2000).

55. Rahman, A. et al. Galpha(q) and Gbetagamma regulate PAR-1 signaling of thrombin-induced NF-kappaB activation and ICAM-1 transcription in endothelial cells. Circ. Res. 91, 398-405 (2002).

56. Roebuck, K. A. \& Finnegan, A. Regulation of intercellular adhesion molecule-1 (CD54) gene expression. J. Leukoc. Biol. 66, 876-888 (1999).

57. Marin, E. P., Derakhshan, B., Lam, T. T., Davalos, A. \& Sessa, W. C. Endothelial cell palmitoylproteomic identifies novel lipid-modified targets and potential substrates for protein acyl transferases. Circ. Res. 110, 1336-1344 (2012). 
58. Parat, M. O., Stachowicz, R. Z. \& Fox, P. L. Oxidative stress inhibits caveolin-1 palmitoylation and trafficking in endothelial cells. Biochem. J. 361, 681-688 (2002).

59. Sanchez, F. A. et al. Functional significance of differential eNOS translocation. Am. J. Physiol. Heart Circ. Physiol. 291, H1058-H1064 (2006).

60. Yuan, S. Y. New insights into eNOS signaling in microvascular permeability. Am. J. Physiol. Heart Circ. Physiol. 291, H1029-H1031 (2006).

61. Wei, X. et al. De novo lipogenesis maintains vascular homeostasis through endothelial nitric-oxide synthase (eNOS) palmitoylation. J. Biol. Chem. 286, 2933-2945 (2011).

62. Tinsley, J. H., Breslin, J. W., Teasdale, N. R. \& Yuan, S. Y. PKC-dependent, burn-induced adherens junction reorganization and barrier dysfunction in pulmonary microvascular endothelial cells. Am. J. Physiol. Lung Cell. Mol. Physiol. 289, L217-L223 (2005).

63. Sun, C. et al. ADAM15 deficiency attenuates pulmonary hyperpermeability and acute lung injury in lipopolysaccharide-treated mice. Am. J. Physiol. Lung Cell. Mol. Physiol. 304, L135-L142 (2013).

64. Zhou, Y. et al. Canonical WNT signaling components in vascular development and barrier formation. J. Clin. Investig. 124, 3825-3846 (2014).

65. Sperandio, M., Pickard, J., Unnikrishnan, S., Acton, S. T. \& Ley, K. Analysis of leukocyte rolling in vivo and in vitro. Methods Enzymol. 416, 346-371 (2006).

66. Beard, Jr. R. S. et al. Non-muscle Mlck is required for beta-catenin- and FoxO1-dependent downregulation of Cldn5 in IL-1beta-mediated barrier dysfunction in brain endothelial cells. J. Cell Sci. 127, 1840-1853 (2014).

67. Gao, X. \& Hannoush, R. N. Single-cell in situ imaging of palmitoylation in fatty-acylated proteins. Nat. Protoc. 9, 2607-2623 (2014).

68. Ren, W., Jhala, U. S. \& Du, K. Proteomic analysis of protein palmitoylation in adipocytes. Adipocyte 2, 17-28 (2013).

\section{Acknowledgements}

This work was supported in part by the National Institutes of Health grants HL070752, HL126646 and GM097270, and by the VA Merit Review BX000799.

\section{Author contributions}

R.S.B.J. and X.Y. designed, performed, analysed and interpreted most of the experiments J.E.M. participated in cell culture, mRNA isolation and RT-PCR. J.W.O. participated in animal maintenance and mutagenesis experiments. C.Y., J.E.E. and C.D.P participated in hydraulic conductivity and transvascular flux measurements. B.J.C. assisted with confocal imaging and live-cell calcium imaging. D.A.M. and R.J.D. contributed to click chemistry and acyl-biotin exchange experiments. M.H.W. contributed to the design and data analysis of in vivo experiments. S.Y.Y. initiated, designed, directed and supported the work through all levels of development. All the authors discussed the results and approved the manuscript.

\section{Additional information}

Supplementary Information accompanies this paper at http://www.nature.com/ naturecommunications

Competing financial interests: The authors declare no conflict of interests.

Reprints and permission information is available online at http://npg.nature.com/ reprintsandpermissions/

How to cite this article: Beard, R. S. et al. Palmitoyl acyltransferase DHHC21 mediates endothelial dysfunction in systemic inflammatory response syndrome. Nat. Commun. 7:12823 doi: 10.1038/ncomms12823 (2016).

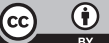

This work is licensed under a Creative Commons Attribution 4.0 International License. The images or other third party material in this article are included in the article's Creative Commons license, unless indicated otherwise in the credit line; if the material is not included under the Creative Commons license, users will need to obtain permission from the license holder to reproduce the material. To view a copy of this license, visit http://creativecommons.org/licenses/by/4.0/

\footnotetext{
(C) The Author(s) 2016
} 